\title{
Observation and a numerical study of gravity waves during tropical cyclone Ivan (2008)
}

\author{
F. Chane Ming ${ }^{1}$, C. Ibrahim ${ }^{1}$, C. Barthe ${ }^{1}$, S. Jolivet ${ }^{2}$, P. Keckhut ${ }^{3}$, Y.-A. Liou ${ }^{4}$, and Y. Kuleshov ${ }^{5,6}$ \\ ${ }^{1}$ Université de la Réunion, Laboratoire de l'Atmosphère et des Cyclones, UMR8105, CNRS-Météo France-Université, La \\ Réunion, France \\ ${ }^{2}$ Singapore Delft Water Alliance, National University of Singapore, Singapore, Singapore \\ ${ }^{3}$ Laboratoire Atmosphères, Milieux, Observations Spatiales, UMR8190, Institut Pierre-Simon Laplace, Université \\ Versailles-Saint Quentin, Guyancourt, France \\ ${ }^{4}$ Center for Space and Remote Sensing Research, National Central University, Chung-Li 3200, Taiwan \\ ${ }^{5}$ National Climate Centre, Bureau of Meteorology, Melbourne, Australia \\ ${ }^{6}$ School of Mathematical and Geospatial Sciences, Royal Melbourne Institute of Technology (RMIT) University, Melbourne, \\ Australia
}

Correspondence to: F. Chane Ming (fchane@univ-reunion.fr)

Received: 3 December 2012 - Published in Atmos. Chem. Phys. Discuss.: 24 April 2013

Revised: 21 November 2013 - Accepted: 2 December 2013 - Published: 22 January 2014

\begin{abstract}
Gravity waves (GWs) with horizontal wavelengths of 32-2000 km are investigated during tropical cyclone (TC) Ivan (2008) in the southwest Indian Ocean in the upper troposphere (UT) and the lower stratosphere (LS) using observational data sets, radiosonde and GPS radio occultation data, ECMWF analyses and simulations of the French numerical model Meso-NH with vertical resolution $<150 \mathrm{~m}$ near the surface and $500 \mathrm{~m}$ in the UT/LS. Observations reveal dominant low-frequency GWs with short vertical wavelengths of $0.7-3 \mathrm{~km}$, horizontal wavelengths of $80-400 \mathrm{~km}$ and periods of $4.6-13 \mathrm{~h}$ in the UT/LS. Continuous wavelet transform and image-processing tools highlight a wide spectrum of GWs with horizontal wavelengths of $40-1800 \mathrm{~km}$, short vertical wavelengths of $0.6-3.3 \mathrm{~km}$ and periods of $20 \mathrm{~min}-$ 2 days from modelling analyses. Both ECMWF and Meso$\mathrm{NH}$ analyses are consistent with radiosonde and GPS radio occultation data, showing evidence of a dominant TCrelated quasi-inertia $\mathrm{GW}$ propagating eastward east of TC Ivan with horizontal and vertical wavelengths of $400-800 \mathrm{~km}$ and $2-3 \mathrm{~km}$ respectively in the LS, more intense during TC intensification. In addition, the Meso- $\mathrm{NH}$ model produces a realistic, detailed description of TC dynamics, some highfrequency GWs near the TC eye, variability of the tropospheric and stratospheric background wind and TC rainband characteristics at different stages of TC Ivan. A wave num-
\end{abstract}

ber 1 vortex Rossby wave is suggested as a source of dominant inertia GW with horizontal wavelengths of $400-800 \mathrm{~km}$, while shorter scale modes (100-200 km) located at northeast and southeast of the TC could be attributed to strong localized convection in spiral bands resulting from wave number 2 vortex Rossby waves. Meso-NH simulations also reveal GWrelated clouds east of TC Ivan.

\section{Introduction}

Mesoscale organized convective systems such as tropical cyclones (TCs) have been known to be intense sources of lowfrequency convective gravity waves (GWs). Observations reveal that such GWs have horizontal wavelengths of 10 $2000 \mathrm{~km}$, vertical wavelengths of $1-6 \mathrm{~km}$ and periods of $1 \mathrm{~h}-$ 2.5 days in the upper troposphere (UT) and the lower stratosphere (LS) above TC basins (Pfister et al., 1993; Sato et al., 1993; Chane Ming et al., 2002, 2010; Dhaka et al., 2003; Niranjan Kumar et al., 2011; Das et al., 2012). Recently, using radiosonde data, Chane Ming et al. (2010) also demonstrated a possible correlation between daily maximum surface wind speed and total energy density of inertia GWs produced by intense TCs Dina and Faxai in the UT/LS. Ibrahim et al. (2010) extended this study analysing a climatology of 
10 TC seasons (1997/1998-2006/2007) and radiosonde data obtained at Tromelin Island $\left(15.53^{\circ} \mathrm{S}, 54.31^{\circ} \mathrm{E}\right)$ located in the southwest Indian Ocean (SWIO). Results suggest a possible linear relationship between weekly GW total energy density in the LS and cyclone days of intense TCs in the SWIO.

Non-orographic GWs triggered by deep convection play an important role in tropical dynamics (Piani et al., 2000; Lane and Reeder, 2001), in particular in the quasi-biennal oscillation (Baldwin et al., 2001) and the mesopause semiannual oscillation (Dunkerton, 1982) in the equatorial region. As various source mechanisms of such intermittent small-scale waves are not clearly understood, observations as well as high-resolution mesoscale numerical modelling are needed to improve parameterizations of such poorly understood processes in weather forecasting and climate models (Kim et al., 2003; Alexander et al., 2010). In particular, GW drag parameterizations fail to correctly represent nonorographic GWs produced by convection in general circulation models because of wide spectrum of $\mathrm{GW}$ frequencies, phase speeds, and spatial scales depending on properties of convection and the environment (Richter et al., 2010). Thus GW drag parameterizations require a set of observations of source properties covering a wide spectral range to constrain tunable parameters for realistic global behaviour of both orographic and non-orographic GWs through GW momentum fluxes (Alexander, 2003; Fritts and Alexander, 2003). Therefore implementation of GW momentum flux parameterizations dedicated to specific convective source processes in global climate models is a current research topic (Ern and Preusse, 2012). For example, Kim and Chun (2005) suggested a computationally efficient non-orographic GW parameterization scheme producing reasonably accurate variation of the momentum flux generated by convective heat sources for global atmospheric prediction models in the middle atmosphere.

Presently, prediction of TC intensification is limited by our understanding of TC structure and multiscale interaction inside and with the environment. Wave processes, especially in the inner core dynamics, and their relationship with spiral rainbands are not fully understood. Recent numerical studies suggest that weakening of simulated TCs is closely associated with environmentally induced asymmetries that develop in the vicinity of the TC eye wall (Wu and Braun, 2004). The movement of storm through the surrounding atmosphere and the wind shear are major causes of an asymmetric distribution of rainband structures (Reasor et al., 2000; Houze, 2010). In a low-shear environment, rainfall is mainly located in the regions ahead of a storm, especially in the outer rainband regions, otherwise it is located downshear left (right) in the Northern (Southern) Hemisphere (Wu and Braun, 2004). When TC intensity increases, the asymmetry maximum shifts upwind to the left in the Northern Hemisphere.

Indeed, sources of GWs and effects on TC structure still remain an open debate (Chow and Chan, 2003; Schubert et al., 2007; Schecter, 2008; Hendricks et al., 2008). Current sophisticated mesoscale numerical models have shown evidence of GWs in the inner core and rainbands in highresolution simulations (Liu et al., 1999; Zhang et al., 2000, 2002; Lin et al., 2011). In explicitly resolving convection, mesoscale numerical models such as MM5 (Fifth-Generation NCAR/Penn State Mesoscale Model PSU/NCAR Mesoscale Model) and AR-WRF (Advanced Research - Weather Research and Forecasting) proved to be useful numerical tools to explore the wide spectrum of TC-generated GWs as well as source mechanisms, propagation and effects on the atmosphere in relation to evolution of the TC dynamics (Kuester et al., 2008; Kim and Chun, 2010). Simulation of TC Saomai (2006) suggested significant momentum deposition in the UT/LS by GWs with short, dominant horizontal wavelengths $(20-100 \mathrm{~km})$ and frequencies $(0.3-2 \mathrm{~h})$ and possible impact on the TC development through the modification of the tropospheric vertical wind shear (Kim and Chun, 2011). At present, three major mechanisms - i.e. mechanical oscillator effect (Fovell et al. 1992), obstacle effect (Clark et al., 1986), and thermal heating effect (Salby and Garcia, 1987) are proposed to explain generation of convective GWs.

The present study aims at investigating GWs within a wide range of horizontal scales $(32-2000 \mathrm{~km})$ during TC Ivan (2008) in the SWIO using the French mesoscale numerical model Meso-NH with a large single horizontal domain, a horizontal grid size of $4 \mathrm{~km}$ and explicit deep convection. Characteristics of dominant GWs and their evolution are analysed depending on TC stages using observational data sets (radiosondes, GPS radio occultation (RO) data), ECMWF analyses and Meso-NH simulations. In particular, TC-related GWs and processes which generated the waves are investigated during TC intensification. In regard to TC-related GWs, the evolution and role of spiral rainbands are also briefly addressed.

\section{Overview of tropical cyclone Ivan (2008)}

Developing from a disturbed area of convection with a sustained monsoon flux in the lower layers, the system became well organized northeast of Madagascar on 6 February 2008. Due to a rapid intensification favoured by the passage of a tropopause anomaly above, it reached a stage of moderate tropical storm on 7 February. Moving southeastward, the system oscillated between stages of moderate tropical storm and strong tropical storm on 11 and 12 February. It reversed the direction of its movement from 9 to 12 February, making a complete loop and turning to the west-southwest after 14 February. Encountering new favourable conditions after 14 February, the system re-intensified to a TC stage as it passed over Tromelin Island on 15 February. Then TC Ivan continued moving towards the west-southwest at an average speed of 8 knots $\left(4.1 \mathrm{~m} \mathrm{~s}^{-1}\right)$, becoming a threat to the northeast coast of Madagascar. Tropical Rainfall Measuring 

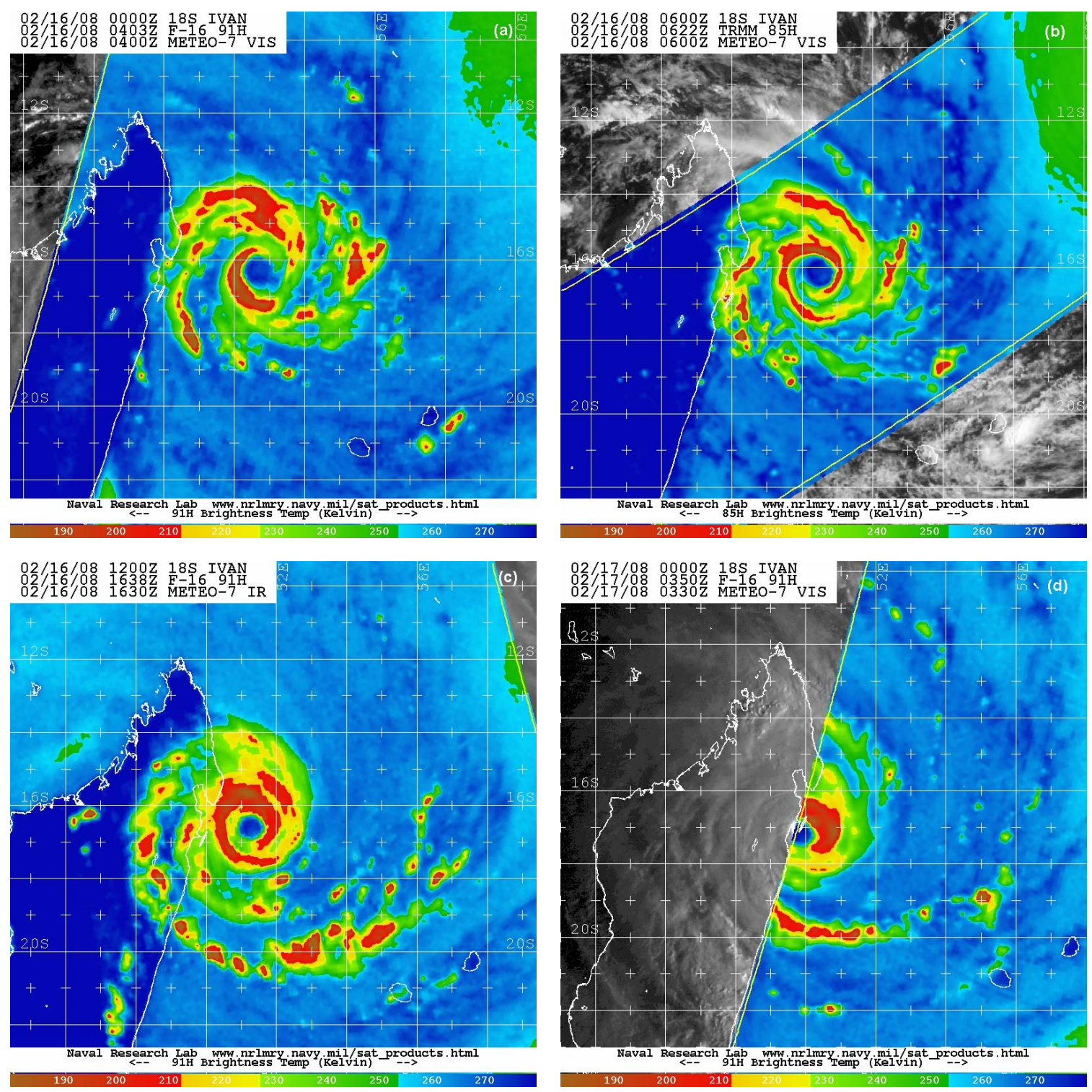

Fig. 1. METEOSAT7 visible images of TC Ivan with (a) F-16 SSMI/S brightness temperatures on 16 February 2008 at 00:00 UTC. (b) TRMM TMI brightness temperatures at $85 \mathrm{H}$ on 16 February 2008 at 06:00 UTC. (c) F-16 SSMI/S brightness temperatures on 16 February 2008 at 16:30 UTC. (d) F-16 SSMI/S brightness temperatures on 17 February 2008 at 00:00 UTC (from http://www.nrlmry.navy.mil/tc_ pages).

Mission precipitation radar captured tall convective activity with high values of reflectivity $(30 \mathrm{dBz})$ at $10-11 \mathrm{~km}$ altitude on 16 February at 06:21 UTC. Tall towers, elevated up to about $13 \mathrm{~km}$ height, were observed in the concentric inner eye wall and in TC spiral rainbands at the beginning of its intensification. Figure 1a shows satellite observation of TC Ivan at the beginning of the intense stage of development on 16 February at 00:00 UTC. Minimum central pressure of $920 \mathrm{hPa}$ and $10 \mathrm{~min}$ averaged maximum sustained winds of 105 knots $\left(54 \mathrm{~m} \mathrm{~s}^{-1}\right)$ were reported on 16 February at 06:00 UTC (Fig. 1b). Figures 1c and d show evidence of a wave number 1 asymmetry characterized by an increase (decrease) of convection close to the eye wall in the northeastern (southwestern) quadrant of the TC on 16 February at 16:30 UTC and 17 February at 00:00 UTC respectively. Eye wall asymmetries are a common feature for TCs and are now considered to be crucial for understanding internal dynamics and variability of TC intensity (Hendricks et al., 2012). Using airborne Doppler radar, Marks et al. (1992) investigated the nature of the altitude-varying wind asymmetry of TC Norbert (1984). The asymmetry perturbations were characterized as a source-sink field at $1 \mathrm{~km}$ heights and a vortex couplet above 
$3 \mathrm{~km}$ altitude (Marks et al., 1992; Liu et al., 1999). Indeed, most of this asymmetry of TC Olivia (1994) could be explained by the azimuthal variance of wave number 1 above $3 \mathrm{~km}$ altitude (Reasor et al., 2000).

On 17 February at 04:00 UTC, TC Ivan passed over Sainte Marie Island and then made landfall in the north of Madagascar at 06:00 UTC with maximum sustained winds of 95 knots $\left(48.9 \mathrm{~m} \mathrm{~s}^{-1}\right)$ and a minimum central pressure of $935 \mathrm{hPa}$ (Fig. 1d). It rapidly weakened into a remnant lowpressure area as it crossed Madagascar. It regenerated over the Mozambique Channel into a tropical depression from 19 February before dissipation on 22 February. Best track data of TC Ivan from 13 February until its landfall in Madagascar are presented in Fig. 2.

\section{Data and methodology}

Characteristics of GWs are derived using upper air data obtained by GPS radiosondes launched at the meteorological stations of Gillot $\left(20.9^{\circ} \mathrm{S}, 55.5^{\circ} \mathrm{E}\right)$ at La Réunion Island and Ivato $\left(18.9^{\circ} \mathrm{S}, 47.8^{\circ} \mathrm{E}\right)$ at Antananarivo in Madagascar, FORMOSAT-3/COSMIC GPS RO data set within the area encompassed by longitudes between 48 and $68^{\circ} \mathrm{E}$ and latitudes between 10 and $22^{\circ} \mathrm{S}$, and ECMWF analyses during TC Ivan in February 2008 (Fig. 2). From 5 February to 27 February, 23 GPS radiosondes were launched daily at 11:00 UTC at the airport of Gillot (21 m altitude). Vertical profiles of temperature and horizontal wind with $100 \mathrm{~m}$ resolution reached the mean altitude of $23 \mathrm{~km}$. Radiosonde data quality and accuracy are described in Chane Ming et al. $(2002,2007,2010)$ and Ibrahim (2010), which used similar vertical profiles to characterize GWs in the UT/LS. At Ivato airport (389 m altitude), 40 GPS radiosonde profiles were obtained twice a day at 00:00 and/or 09:00 and/or 12:00 UTC with a vertical resolution of $300 \mathrm{~m}$ and a mean maximum altitude of $23 \mathrm{~km}$.

The FORMOSAT-3/COSMIC (Formosa Satellite Mission3/Constellation Observing System for Meteorology, Ionosphere, and Climate) data set from the COSMIC Data Analysis and Archive Center (CDAAC) consists of 70 daily soundings of temperature between 2 and $40 \mathrm{~km}$ altitude over the SWIO between 13 and 18 February 2008. Vertical profiles have high accuracy for temperature ( $<1 \mathrm{~K}$ from 5 to $25 \mathrm{~km}$ ) and spatial resolution varying from $100 \mathrm{~m}$ at the surface to $1.5 \mathrm{~km}$ at $35 \mathrm{~km}$ altitude ( $1 \mathrm{~km}$ at the altitude of tropopause) (Pirscher et al., 2010; Anthes, 2011). Collocation mismatch affects the comparison: standard deviation errors are $<0.5 \mathrm{~K}$ for temperature in both the troposphere $(850-200 \mathrm{hPa})$ and the stratosphere, and for relative humidity they are $<3.5 \%$ for $3 \mathrm{~h}$ temporal buffer and $100 \mathrm{~km}$ spatial buffer (Sun et al., 2010; Zhang et al., 2011). GPS RO data observed by lowEarth-orbit satellites have been used previously for GWs observations in the LS (Tsuda et al., 2000; Liou et al., 2003, 2006). A comprehensive introduction to the RO method for

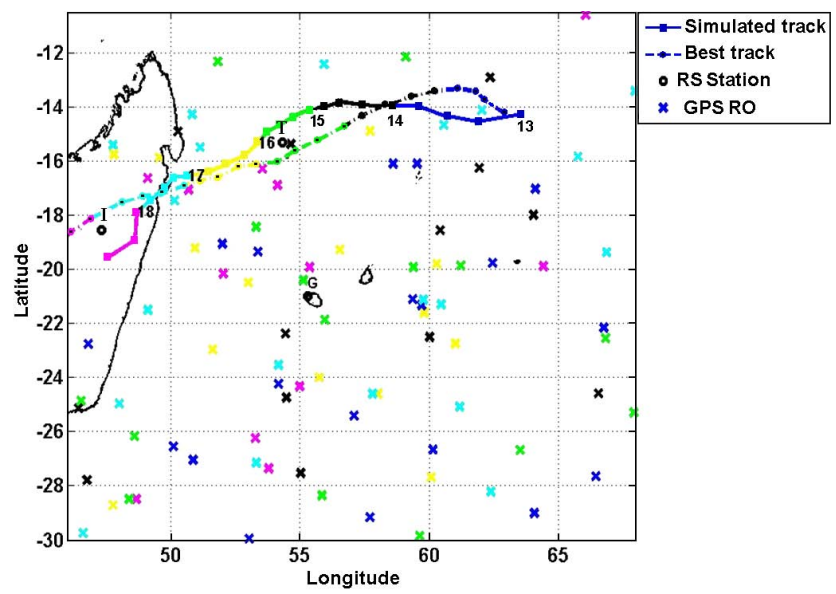

Fig. 2. TC Ivan best track data (RSMC La Réunion, dashed line) and cyclone track data obtained by simulation (Meso-NH, solid line). Crosses indicate locations of GPS RO soundings and black circles correspond to locations of meteorological radio sounding (RS) stations (G: Gillot, I: Ivato, T: Tromelin). Colours of crosses and segments of tracks indicate the day (13 February - navy blue; 14 February - black; 15 February - green; 16 February - yellow; 17 February - light blue; and 18 February - magenta).

remote sensing of the atmosphere and ionosphere is presented in Liou et al. (2010). COSMIC GPS RO profiles have recently been analysed to describe monthly global stratospheric GW energy densities (Alexander et al., 2008; Xiao and $\mathrm{Hu}, 2010$ ).

In the present study, vertical velocities are extracted from 6-hourly ECMWF operational analyses with $1.125^{\circ} \times 1.125^{\circ}$ resolution for the analysis of GWs in the UT/LS. Mountain and jet-stream-forced GWs have been previously derived from ECMWF data (Plougonven and Teitelbaum, 2003; Schroeder et al., 2009). Indeed, current operational numerical weather prediction models (NWPs) are likely to explicitly resolve a large fraction of the observed stratospheric inertia-gravity-wave spectrum with horizontal wavelengths of $100-1000 \mathrm{~km}$ and probably even longer in the tropics (Shutts and Vosper, 2011). Nevertheless, vertical resolution still remains insufficient to capture quasi-inertia-wave energy with vertical wavelengths $<2 \mathrm{~km}$. In addition, high-quality temperature information in ECMWF data has been provided for the UT/LS, more particularly in the Southern Hemisphere, ever since the assimilation of GPS RO bending angles beginning in late December 2006 (Healy and Thepaut, 2006; Healy, 2007). Thus several studies proved that TC simulations are also improved in NWP models (Huang et al., 2010; Kunii et al., 2012; Liu et al., 2012).

Second- and third-order polynomial fits are applied to GPS radiosonde vertical profiles of temperature and wind respectively, using a cubic spline interpolation, and subtracted from the $100 \mathrm{~m}$ resampled vertical profiles to derive 
temperature and wind perturbations induced by GWs. Conventional methods described in Chane-Ming et al. (2010) are applied to vertical profiles of temperature and wind perturbations to extract GW parameters such as energy densities and spectral characteristics. Radiosonde and GPS RO profiles explore low-frequency GWs with short vertical wavelengths limited by vertical height ranges in the UT/LS (Alexander and Barnet, 2007; Chane Ming et al., 2010). In addition the observational filter of GPS RO measurements sets the lower limit of periods at $2 \mathrm{~h}$ (Preusse et al., 2008).

One- and two-dimensional fast Fourier transforms (FFT) and Morlet continuous wavelet transform (CWT) together with other image-processing tools are used to visualize dominant GWs and to extract spectral characteristics of GWs from GPS RO vertical perturbation profiles, ECMWF analyses and Meso-NH outputs. Second-order spectral parameters are derived from the linear relation of GW dispersion.

\section{Numerical modelling}

\subsection{Model description}

The non-hydrostatic mesoscale model Meso-NH (Lafore et al., 1998) is used in this study to simulate development of TC Ivan from 13 to 18 February. The research model has been jointly developed by the Centre National de Recherches Météorologiques (Centre National de la Recherche Scientifique/Météo-France) and Laboratoire d'Aérologie (Centre National de la Recherche Scientifique/Université Paul Sabatier). In previous studies, the model proved to be useful for the simulation of cyclones' development. Nuissier et al. (2005) studied a mature stage of the category 4 TC Bret (1999) in the North Atlantic Basin with the Meso-NH non-hydrostatic, two-way-interactive, quadruple-nested grid mesoscale model initialized with airborne Doppler radar and dropsonde data. Leclaire De Bellevue et al. (2007) focused on tropospheric ozone enhancement at the periphery of TC Marlene in the SWIO. Recently orographic influence of La Réunion Island on the structure and evolution of TC Dina (2002), described in Roux et al. (2004), was numerically examined in Jolivet et al. (2013). In particular, PV estimates revealed that buoyancy waves were generated on the lee side of the island's peak $(3070 \mathrm{~m})$ when peripheral cyclonic flow of the TC impacted on the island.

The present model configuration consists of a single domain with $360 \times 600$ horizontal grid points ( $4 \mathrm{~km}$ resolution) in order to study GWs with horizontal wavelengths between $32 \mathrm{~km}(8 \Delta x)$ (Lane and Knievel, 2005) and 1200-2400 km. The chosen horizontal resolution is in the grey zone regarding the representation of convection (Yu and Lee, 2010). But it is a good compromise for explicit convection to reproduce detailed structures of mesoscale convective systems in TCs (Klemp, 2006). Liu at al. (1999) and Lac et al. (2002) simulated convective GWs with short horizontal wavelengths of
15-80 km with MM5 and Meso-NH models with grid sizes of 6 and $5 \mathrm{~km}$ respectively.

Fifty-five vertical levels are used from the surface to $29 \mathrm{~km}$ altitude with a damping layer at $25 \mathrm{~km}$. Vertical resolution is higher at the surface $(<150 \mathrm{~m})$ for surface flux processes. It becomes gradually coarser in the middle troposphere up to altitudes of $6-7 \mathrm{~km}$ (mean value $<500 \mathrm{~m}$ ) and $\sim 500 \mathrm{~m}$ at altitudes between 10 and $24 \mathrm{~km}$ in the UT/LS.

The simulation started at 00:00 UTC on 13 February 2008 with a time step of $15 \mathrm{~s}$, when TC Ivan begun moving to the southwest in the direction of Tromelin and Madagascar, and ended at 21:00 UTC on 18 February 2008 after its landfall in Madagascar. Thus, the intensification, mature stage and dissipation of TC Ivan are reproduced in the simulation.

Aladin-Réunion analyses were used to initialize Meso$\mathrm{NH}$ and to feed the lateral boundary conditions, which were updated every six hours. Aladin-Réunion is a limited-area model that has been used by Météo-France for TC forecasting in the SWIO at $9.6 \mathrm{~km}$ horizontal resolution since 2006 (Montroty et al., 2008). It better represents TC structure in comparison with global models so that no bogus vortex is used in this model. Physics of the model includes a mixedphase microphysics scheme (Pinty and Jabouille, 1998), and a 1-D turbulence scheme (Cuxart et al., 2000). Shallow convection is parameterized with the scheme of Kain and Fritsch (1990) adapted by Bechtold et al. (2001). The same scheme is used for simulation of deep convection to the resolution of $5 \mathrm{~km}$. At this resolution and below, deep convection is explicitly resolved by the model. The radiative scheme is the one used at ECMWF (Gregory et al., 2000).

\subsection{Validation of simulated TC Ivan track}

A simulated track is compared with best track data prepared by Méteo-France Regional Specialized Meteorological Centre (RSMC) La Réunion (Fig. 2). TC categories used for classification of TC intensity by the RSMC La Réunion are based on $10 \mathrm{~min}$ average maximum sustained winds. After a $24 \mathrm{~h}$ spin-up, a track of TC Ivan is well represented in the model. At the beginning of the simulation, the system moved to the northwest before heading toward Madagascar. This simulated track becomes more consistent with the observed track from the TC intensification stage to its landfall in Madagascar. A position error of less than $50 \mathrm{~km}$ is observed during the intense phase of TC Ivan (from 16 February at 00:00 UTC to 17 February at 21:00 UTC) compared with best track data. Time of landfall on Sainte Marie Island in numerical simulation occurred with a delay of $3 \mathrm{~h}$ compared to observations. A TC tracker algorithm is based on detecting minimum pressure with a location uncertainty of about $10 \mathrm{~km}$. Evolution of the maximum sustained wind speed and minimum central pressure is illustrated in Fig. 3. In the model simulation, the TC intensity is slightly underestimated during the cyclone's mature stage. The minimum central pressure (maximum sustained wind speed) decreases (increases) to a 

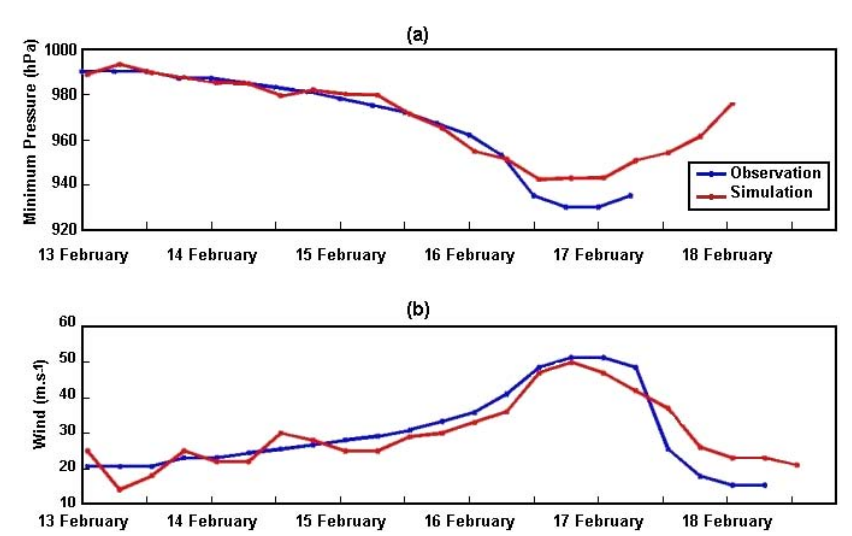

Fig. 3. Time series of (a) the minimum central pressure and (b) the 10 min average maximum sustained wind speed from best track data (blue line) and model simulation (red line).

minimum (maximum) of $940 \mathrm{hPa}\left(53 \mathrm{~m} \mathrm{~s}^{-1}\right)$ until 16 February. The simulated parameters are in good agreement with the observations after the spin-up phase.

Synthetic brightness temperatures corresponding to the Meteosat Second Generation (MSG) observations in the infrared channels were computed from Meso-NH outputs using the Radiative Transfer for Tiros Operational Vertical Sounder (RTTOV) code version 8.7 (Saunders et al., 2005) and compared with observations (Chaboureau et al., 2000). Brightness temperatures observed with Meteosat- 7 and computed from Meso-NH outputs on 16 February 2008 at 00:00 UTC for the intense stage of TC Ivan are presented in Fig. 4. Meso-NH reproduces a TC eye characterized by a zone of high brightness temperature in the centre of TC Ivan ( $218 \mathrm{~K}$ for Meteosat-7 and $214 \mathrm{~K}$ for Meso-NH). An asymmetry of the system is well represented with an area of more intense convection in the northeastern quadrant characterized by low values of brightness temperature (192 and $190 \mathrm{~K}$ for observations and Meso-NH respectively). This area is more extended for the Meso-NH simulation at this time.

Simulated temperature and wind fields on 15 and 16 February at 00:00 UTC in the outer region of the storm are also examined. Both radiosonde and GPS RO vertical profiles of temperature are quite consistent with simulated fields of the environment in the troposphere at altitudes between 1 and $25 \mathrm{~km}$ with relative mean errors $<1.5 \%$ at distances of 650 and $825 \mathrm{~km}$ from the centre of TC Ivan respectively (Fig. 5a). A general behaviour of temperatures is correctly simulated in the outer region of the storm in the troposphere (Fig. 5a, b). Differences observed in mean temperature above $20 \mathrm{~km}$ at a distance of $650 \mathrm{~km}$ do not affect GWs on profiles of temperature perturbations below $20 \mathrm{~km}$ altitude (Fig. 5a). In addition, variations of mean simulated horizontal winds (Fig. 5c, d) are in good agreement with observed wind fields (mean relative error of about $5 \%$ ) at altitudes between 5 and $25 \mathrm{~km}$. Vertical behaviour of mean horizontal wind affects vertical propagation of GWs in the UT/LS through critical level filtering.

Consequently, track, intensity and structure as well as the outer environment of TC Ivan are well simulated by Meso$\mathrm{NH}$ for a realistic study of GWs.

\section{Characteristics of GWs}

\subsection{Radiosonde and GPS radio occultation data}

Spectral characteristics of GWs with short vertical wavelengths $(0.6-4 \mathrm{~km})$ are first derived in the UT $(10-15 \mathrm{~km})$ and the LS $(18-22 \mathrm{~km})$ from a radiosonde data set during the TC stage of Ivan from 15 to 18 February using conventional methods (Table 1). The altitude range of radiosonde data above Ivato limits the study to the UT. Lowfrequency GWs are observed with shorter periods in the UT ( $4 \mathrm{~h}, 6-8 \mathrm{~h})$ than in the LS (13 h). GWs have short dominant vertical wavelengths of $1-2.6 \mathrm{~km}$ and horizontal wavelengths of $70-210 \mathrm{~km}$ in the UT. Horizontal wavelengths are $<400 \mathrm{~km}$ in the LS above Gillot. Rotary spectral analyses provide dominant eastward horizontal direction of GW propagation (40-70 ${ }^{\circ}$ from north) in the UT and LS from 16 to 18 February above Gillot. Horizontal phase speeds of 3.58 and $10.75 \mathrm{~m} \mathrm{~s}^{-1}$ are estimated for horizontal wavelengths of 130 and $390 \mathrm{~km}$ respectively in the LS from 16 to 18 February. A maximum upward energy of $70 \%$ in both the UT and the LS suggests that dominant sources of observed GWs are mostly located below $10 \mathrm{~km}$. Upward energy peaks at $58-70 \%$ in the UT during landfall after the passage of the TC above Ivato. Thus, different processes might be involved in the generation of GWs above the two meteorological stations before and after landfall (Chane Ming et al., 2002, 2010).

Daily dominant vertical wavelengths $<5 \mathrm{~km}$ with periods $>2 \mathrm{~h}$ are computed from 70 profiles of GPS RO data from 13 to 18 February in the UT $(10-15 \mathrm{~km})$ and the LS $(18-24 \mathrm{~km})$. A dominant vertical wavelength of $3 \mathrm{~km}$ is observed during the whole period in the UT and the LS above the SWIO basin, especially east of TC Ivan (Fig. 6). In the LS, energy intensity of the $3 \mathrm{~km}$ vertical mode is greater from the intensification to landfall of TC Ivan (from 15 to 18 February) and maximal during TC intensification on 16 February. The opposite is observed in the UT. The contrast in energy intensification in the UT and the LS is consistent with climatological observations of GW activity during TC seasons (Ibrahim et al., 2010).

Vertical wavelengths of collocated profiles of GPS RO temperature fluctuations and radiosonde data (distance $<100 \mathrm{~km}$ and time $<3 \mathrm{~h}$ ) on 15 and 16 February at Gillot and Ivato are also examined. A dominant mode of $3 \mathrm{~km}$ vertical wavelength is observed in radiosonde and GPS RO profiles in the UT/LS on 15 February above Gillot (Fig. 7). Better vertical resolution of radiosonde data at Gillot enables observation of smaller vertical wavelengths of $\sim 700 \mathrm{~m}$ in the LS. A dominant mode with a vertical wavelength of $1.6 \mathrm{~km}$ in 
(a)

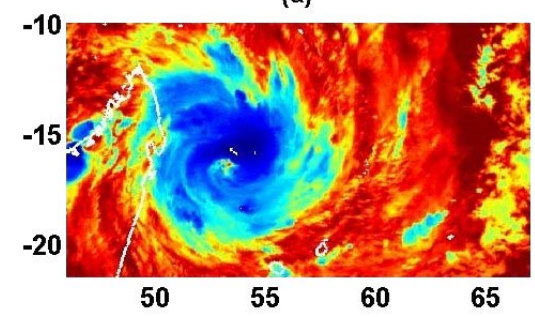

(b)

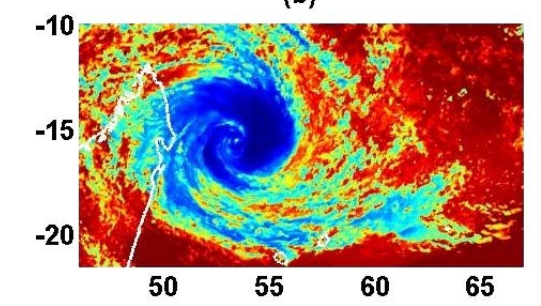

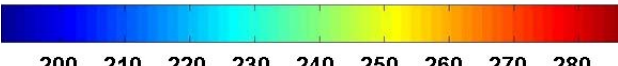

Fig. 4. Brightness temperature (K) from (a) IR channel of Meteosat7 and (b) Meso-NH outputs on 16 February 2008 at 00:00 UTC.
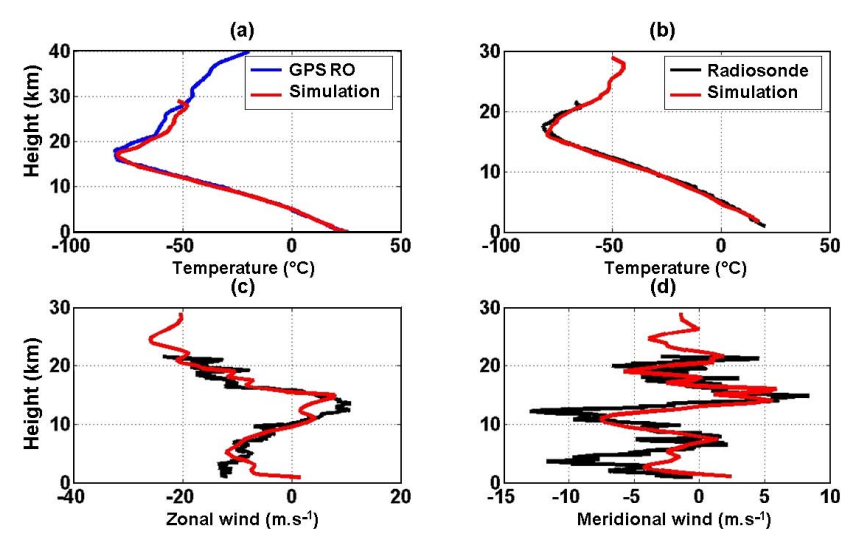

Fig. 5. Observed (black - radiosonde; blue - GPS RO) and simulated (red) vertical profiles of (a) temperature from GPS RO at $\left(19^{\circ} \mathrm{S}, 59^{\circ} \mathrm{E}\right)$ on 15 February at 00:26 UTC (00:00 UTC), (b) temperature of radiosonde at Gillot on 16 February at 11:12 UTC (12:00 UTC), and radiosonde zonal wind (c) and meridional wind (d) at Gillot on 16 February 2008 at 11:12 UTC.

the LS is also present on FFT spectra above Ivato. GWs have a broader spectrum of vertical wavelengths $>1 \mathrm{~km}$ above Ivato located in an orographic region. In addition, FFT energy is more intense both in the UT and the LS above Gillot, in contrast to that above Ivato which is located ahead of TC Ivan, especially in the UT.

In summary, radiosonde and GPS RO profiles show evidence of consistent observations of low-frequency GWs. Dominant GWs with vertical wavelengths of $0.7-1.6 \mathrm{~km}$ and $2-3 \mathrm{~km}$ are observed in the UT/LS above Gillot and Ivato during TC Ivan. In addition they reveal the presence of an
Table 1. Spectral characteristics of GWs above radiosonde stations of Gillot and Ivato from 15 to 18 February $2008\left(\lambda_{\mathrm{h}}\right.$ and $\lambda_{\mathrm{V}}$ : horizontal and vertical wavelengths).

\begin{tabular}{lllll}
\hline $\begin{array}{l}\text { Station } \\
\text { (altitude) }\end{array}$ & $\begin{array}{l}\text { Number of } \\
\text { profiles }\end{array}$ & $\begin{array}{l}\text { Intrinsic } \\
\text { period }(\mathrm{h})\end{array}$ & $\begin{array}{l}\lambda_{\mathrm{h}} \\
(\mathrm{km})\end{array}$ & $\begin{array}{l}\lambda_{\mathrm{V}} \\
(\mathrm{km})\end{array}$ \\
\hline Gillot $(10-15 \mathrm{~km})$ & 4 & $7.6,4$ & 84,210 & $1,2.6$ \\
Gillot $(18-22 \mathrm{~km})$ & 3 & 13 & 130,390 & $0.68,2.1$ \\
Ivato $(10-15 \mathrm{~km})$ & 6 & 4,6 & 66,130 & $1.7,2.6$ \\
\hline
\end{tabular}
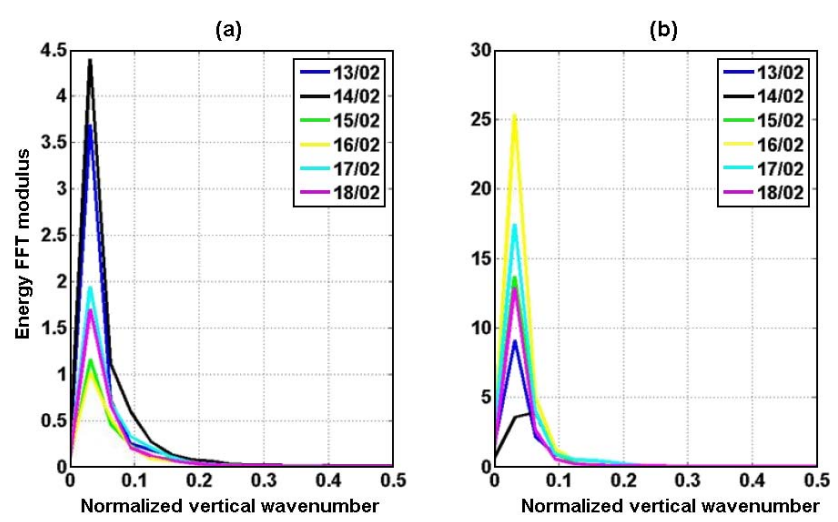

Fig. 6. Fast Fourier transform spectra of 70 GPS RO temperature perturbations from 13 February to 18 February 2008 in (a) the UT and (b) the LS ( $\lambda_{v}=100 \mathrm{~m} /$ normalized frequency).

inertia GW with a vertical wavelength of $2-3 \mathrm{~km}$, horizontal wavelength of $\sim 400 \mathrm{~km}$, period of $13 \mathrm{~h}$ east of TC Ivan in the LS. This inertia GW propagates eastward in the LS. Its intensity is larger east of the TC and peaks during TC intensification.

\subsection{ECMWF analyses}

A spatial high-pass bidirectional 2-D filter, a separable eightneighbour Laplacian (Pratt, 2001), is applied on vertical velocity derived from ECMWF analyses for edge detection of wavelike patterns. Filtered vertical velocity shows evidence of semi-circular waves with a dominant horizontal wavelength of about $600 \mathrm{~km}$ east of TC Ivan which are visualized within a distance as far as four times the horizontal wavelength $(2500 \mathrm{~km})$ at $21 \mathrm{~km}$ altitude in the LS on 16 February 2008 (Fig. 8a). More intense and concentric similar patterns in the UT at $13 \mathrm{~km}$ altitude during the intensification of TC Ivan are indicative of background wind filtering above $13 \mathrm{~km}$ (cf. wind reversal in Fig. 5c) for westward propagating modes with horizontal wavelengths of about $600 \mathrm{~km}$ and the location of GW sources in the UT. The centre of concentric patterns is located on the northwestern side at a distance of $350 \mathrm{~km}$ from the $\mathrm{TC}$ centre $\left(16.5^{\circ} \mathrm{S}, 53^{\circ} \mathrm{E}\right)$.

In Fig. 8b, an FFT analysis of vertical velocity at latitudes of the TC centre $\left(16.5^{\circ} \mathrm{S}\right)$ and observed GWs $\left(9-21^{\circ} \mathrm{S}\right)$ also reveals the presence of other wavelike structures with 
(a)

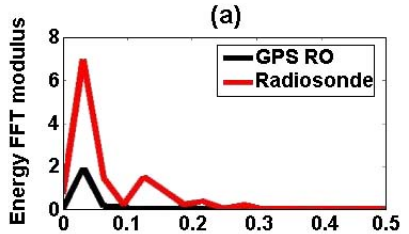

(c)

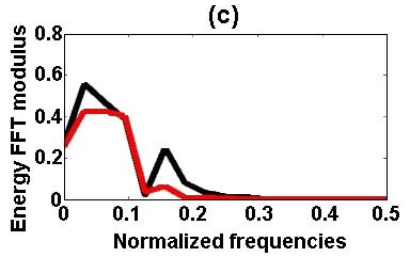

(b)

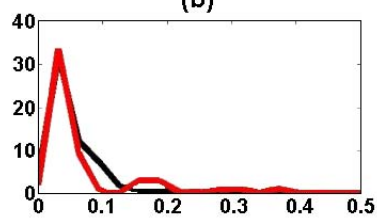

(d)

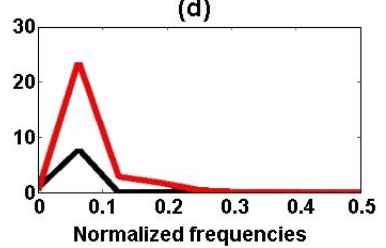

Fig. 7. Fast Fourier transform of collocated GPS RO temperature perturbations on 15 February 2008 in (a) the UT and (b) the LS above Gillot. (c) and (d) same as (a) and (b) but on 16 February 2008 above Ivato $\left(\lambda_{v}=100 \mathrm{~m} /\right.$ normalized frequency $)$.

horizontal wavelengths of $460,860,1100$ and $1700 \mathrm{~km}$, for which spectral peaks are maximum at latitudes close to TC centre. The horizontal wavelength-latitude diagram clearly indicates that most of the energy is distributed between 7 and $21^{\circ} \mathrm{S}$ latitude (Fig. 8c). A line of symmetry is at latitudes of about $14-16^{\circ} \mathrm{S}$. Waves with long horizontal wavelengths of $1400-1700 \mathrm{~km}$ are observed only at latitudes of $15-16.5^{\circ} \mathrm{S}$, whereas those with horizontal wavelengths of about $600 \mathrm{~km}$ are dominant at a distance of about $300 \mathrm{~km}$ from the TC eye.

CWT is applied to the vertical velocity at the latitude of the TC eye to locate observed horizontal modes (Chane-Ming et al., 1999). Longitude-horizontal-wavelength distribution derived from CWT modulus shows evidence of modes with $350-1000 \mathrm{~km}$ horizontal wavelengths peaking at $\sim 550 \mathrm{~km}$ at a latitude of $61^{\circ} \mathrm{S}$ east of TC Ivan (Fig. 8d). A dominant mode of about $800 \mathrm{~km}$ horizontal wavelength is present ahead of the TC eye. In addition the CWT diagram reveals the possible presence of a longer mode with $1700 \mathrm{~km}$ horizontal wavelength ahead of TC Ivan.

The observed phase relations between perturbation zonal, meridional, and vertical winds and temperature at a latitude of $16.5^{\circ} \mathrm{S}$ agree with linear gravity wave theory for the dominant observed GWs (Gill, 1982). The ratio between the CWT modulus of horizontal wind perturbations is computed for the continuous spectrum of GWs with horizontal wavelengths between 350 and $1000 \mathrm{~km}$ to determine the intrinsic period from equation 1 in Chane Ming et al. (2002). Mean periods of $14 \mathrm{~h}$ and $12.8 \mathrm{~h}$ are obtained for the whole area and east of TC eye respectively. The ratio between CWT modulus of zonal and vertical wind perturbations provides vertical wavelengths of $1-2 \mathrm{~km}$ for the dominant mode of $600 \mathrm{~km}$ horizontal wavelength and $12.8 \mathrm{~h}$ period. Mean horizontal and vertical observed phase speeds are estimated to be about 13 and $-0.04 \mathrm{~m} \mathrm{~s}^{-1}$ respectively. A mean period of 1-1.8 days is obtained for GWs with horizontal wavelengths between 1400 and $1700 \mathrm{~km}$ with a dispersive vertical wavelength of
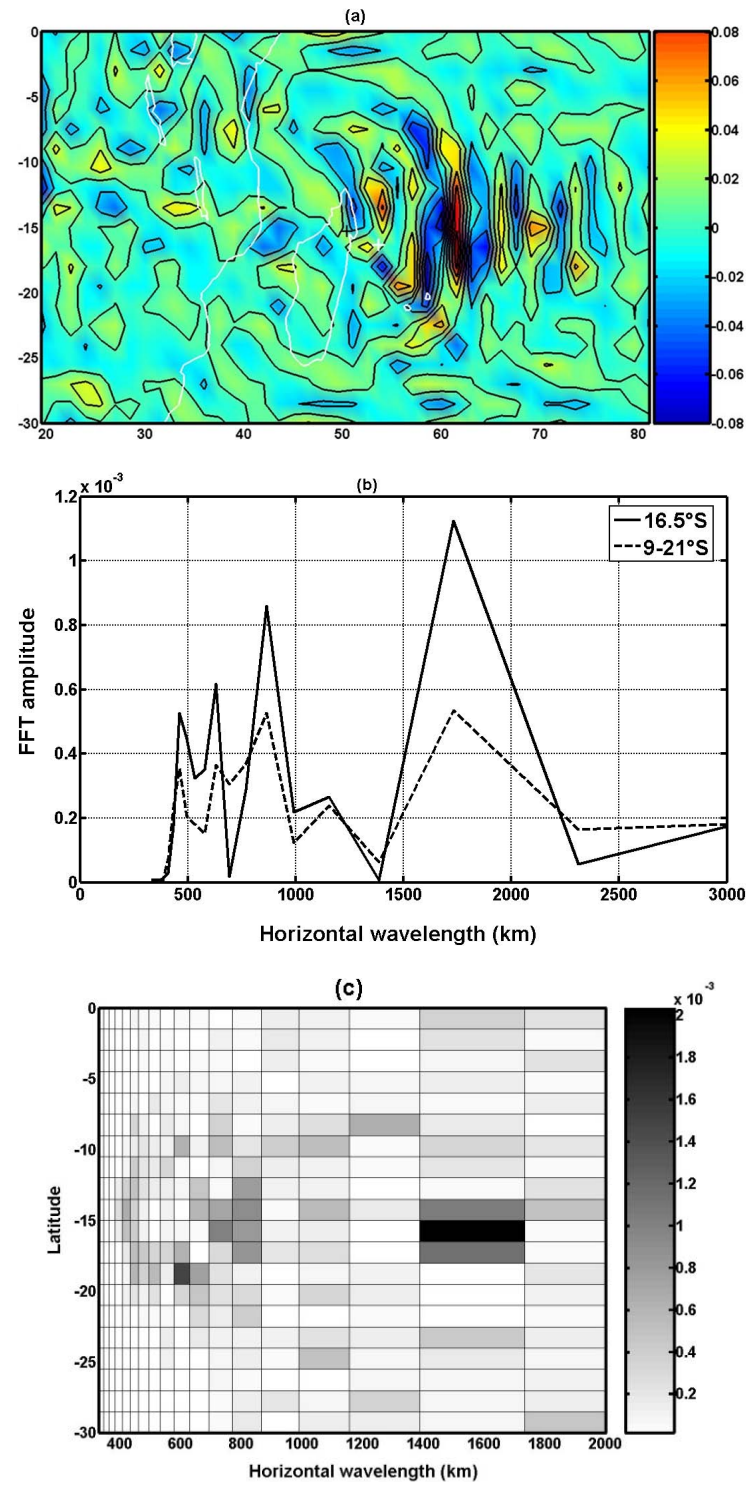

(d)

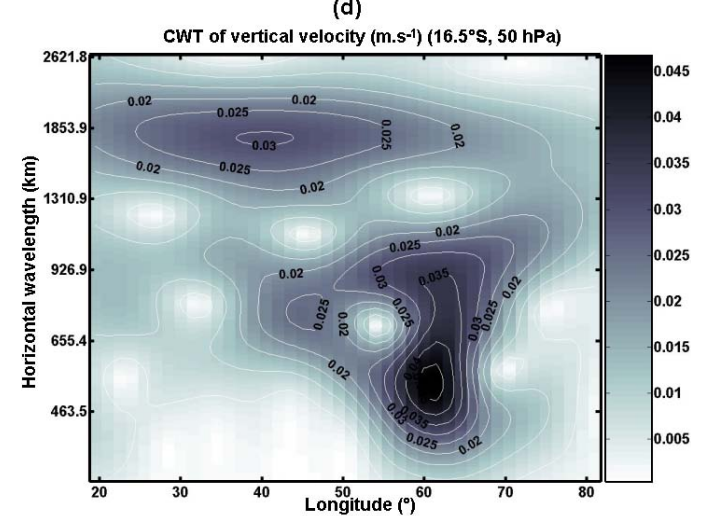

Fig. 8. (a) Vertical velocity ( $\mathrm{m} \mathrm{s}^{-1}$, colour bar) at $50 \mathrm{hPa}$ derived from ECMWF analyses on 16 February 2008 (00:00 UTC). The black (white) cross shows the centre of the semi-circular waves (TC Ivan). Fast Fourier transform of vertical velocity (b) at latitudes of $16.5^{\circ} \mathrm{S}$ and $9-21^{\circ} \mathrm{S}$ and (c) as a function of latitude. (d) Morlet continuous wavelet transform of vertical velocity at $16.5^{\circ} \mathrm{S}$. 
4-10 km. Such periods correspond to inertial periods for latitudes between 5 and $15^{\circ} \mathrm{S}$. Mean horizontal and vertical phase speeds vary between 10 and $20 \mathrm{~m} \mathrm{~s}^{-1}$ and between -0.03 and $-0.08 \mathrm{~m} \mathrm{~s}^{-1}$ respectively.

Both FFT and CWT distribution suggest that winds have a directional filtering effect on propagation of TC-induced GWs from the UT to the LS.

Finally, observations of circular patterns are consistent with previous studies on GWs triggered by convective turrets (Dewan et al. 1998; Piani et al., 2000; Lane and Reeder, 2001; Horinouchi et al., 2002). ECMWF analyses also support that TC-related convection produces a large spectrum of low-frequency GWs in the UT/LS. In particular, a dominant mode of horizontal and vertical wavelengths of 600 and 1$2 \mathrm{~km}$ respectively and $12.8 \mathrm{~h}$ period is observed east of the TC with an eastward propagation of about $13 \mathrm{~m} \mathrm{~s}^{-1}$ favoured by the westward background wind above the tropopause. Estimated vertical wavelength of $1-2 \mathrm{~km}$ might be biased because it is probably not resolved by the ECMWF. Thus, the model describes mostly the low-frequency part of GW spectrum with horizontal wavelengths of 350-2000 km in agreement with Shutts and Vosper (2011).

\subsection{Simulated GWs}

Vertical profiles of meridional wind perturbations are extracted from the simulation every $10 \mathrm{~min}$ to examine smallscale vertical wave activity from 13 February at 00:00 UTC to 18 February at 12:00 UTC above Tromelin Island, which is located on the track of TC Ivan (Fig. 9a). A third-order polynomial fit is used to derive vertical profiles of perturbations. Wave activity with a vertical wavelength of about $2.5-3 \mathrm{~km}$ is clearly observed in the UT up to $25 \mathrm{~km}$ altitude during the development stage of TC Ivan from 14 to 15 February. The downward phase progression estimated at about $-0.08 \mathrm{~m} \mathrm{~s}^{-1}$ reveals an upward energy propagation of convective GWs. It suggests that GW sources are located below the UT during the stage of tropical storm. GW activity increases in the UT at altitudes of $13-15 \mathrm{~km}$ and in the lowermost stratosphere after the passage of TC Ivan over Tromelin Island during TC intensification. A downward phase progression between -0.02 and $-0.06 \mathrm{~m} \mathrm{~s}^{-1}$ is visualized from 16 February. Amplitudes of simulated horizontal wind perturbations $\left(\sim 3-4 \mathrm{~m} \mathrm{~s}^{-1}\right)$ agree with observation. The activity weakens during the mature stage and increases in the UT again during landfall on 17 February. Wavelike structures with longer vertical wavelengths of about $3-4 \mathrm{~km}$ and a clear upward phase progression $\left(0.06 \mathrm{~m} \mathrm{~s}^{-1}\right)$ are also visualized in the middle troposphere at altitudes of $5-10 \mathrm{~km}$ on the later part of 16 February during the mature stage of the TC. They are more intense in the afternoon on 17 February during landfall of TC Ivan and on 18 February. Large GW energy density was previously observed in the UT/LS during intensification of TC Dina (Chane Ming et al., 2010) and landfalls of TC Hudah (2000) over Madagascar and Mozambique (Chane Ming et al., 2002). Time series of vertical GW momentum flux are computed with $10 \mathrm{~min}$ simulated vertical profiles of horizontal and vertical perturbations and averaged over altitude ranges in the UT (12-19 km) and LS (19-25 km) (Sato, 1993; Kim and Chun, 2010). They provide mean values of 0.01 and $5-6 \times 10^{-4} \mathrm{~N} \mathrm{~m} \mathrm{~s}^{-2}$ in the UT and the LS, respectively, above Tromelin and La Réunion islands. Sato (1993) mentioned a maximum momentum flux of $0.04 \mathrm{~N} \mathrm{~m}^{-2}$ at $20 \mathrm{~km}$ during TC Kelly (1987), and Kuester et al. (2008) estimated an integrated average value of $8.1 \times 10^{-4} \mathrm{~N} \mathrm{~m}^{-2}$ in the LS during TC lifetime.

Simulated vertical profiles of mean zonal wind at Gillot display strong westward winds above the surface from 16 February until TC landfall (Fig. 9b). They are accompanied by stronger eastward zonal wind below the tropopause during TC intensification and landfall where strong GW activity occurs. Westward wind at $4 \mathrm{~km}$ altitude increases during intensification. Strong westward winds are also visualized above $25 \mathrm{~km}$ in the LS during TC intensification and at $23-25 \mathrm{~km}$ altitude during landfall. Eastward zonal wind, appearing initially in a shallow layer in the UT, increases in strength during cyclone passage to the north, then deepens into the middle troposphere after landfall. Figure 9c shows zonal winds at $300 \mathrm{~km}$ off the TC centre decreasing from 0 to about $-25 \mathrm{~m} \mathrm{~s}^{-1}$ and meridional winds varying between -5 and $5 \mathrm{~m} \mathrm{~s}^{-1}$ at altitudes between 16 and $25 \mathrm{~km}$ on 16 February at 06:00 UTC. In addition eastward winds are observed east of the TC centre in the UT, where GWs with phase speeds within the interval of values taken by the wind speed will likely dissipate at critical layers.

Indeed, time series of vertical profiles of zonal wind from radiosonde data at Mahe $\left(4.66^{\circ} \mathrm{S}, 55.53^{\circ} \mathrm{E}\right)$ show the downward propagation of westward quasi-biennial oscillation (QBO) winds $\left(0.8 \mathrm{~km} \mathrm{month}^{-1}\right)$ from January to late May 2008 located between 20 and $22 \mathrm{~km}$ altitude during TC Ivan and the occurrence of eastward QBO winds above $22 \mathrm{~km}$ altitude in agreement with QBO index at $30 \mathrm{hPa}$ calculated by NOAA/ESRL. Thus GWs with westward horizontal propagation might be filtered by the westward QBO wind in the LS, whereas GWs with eastward horizontal propagation propagating upward are likely to contribute to the eastward QBO wind in the LS above $22 \mathrm{~km}$ altitude. Using radiosonde observations, Vincent and Alexander (2000) previously observed energy density maxima during the QBO westward phase for convective GWs with intrinsic periods of 20 $25 \mathrm{~h}$, horizontal wavelengths of $200-2000 \mathrm{~km}$ (mean value of $100 \mathrm{~km}$ ) and horizontal phase speed of about $10 \mathrm{~m} \mathrm{~s}^{-1}$ in the LS above Coco Island $\left(12^{\circ} \mathrm{S}, 97^{\circ} \mathrm{E}\right)$. Recently, the analysis of SABER/TIMED data supports that QBO winds act as a significant filter in GW propagation depending on the QBO phases (Zhang et al., 2012). Kawatani et al. (2010) also demonstrated that small-scale GWs play an important role during the QBO westward phase in the LS.

Figure 10 shows the vertical cross section of the vertical velocity at $16^{\circ} \mathrm{S}$ of TC Ivan on 16 February at 12:00 UTC. 
(a)

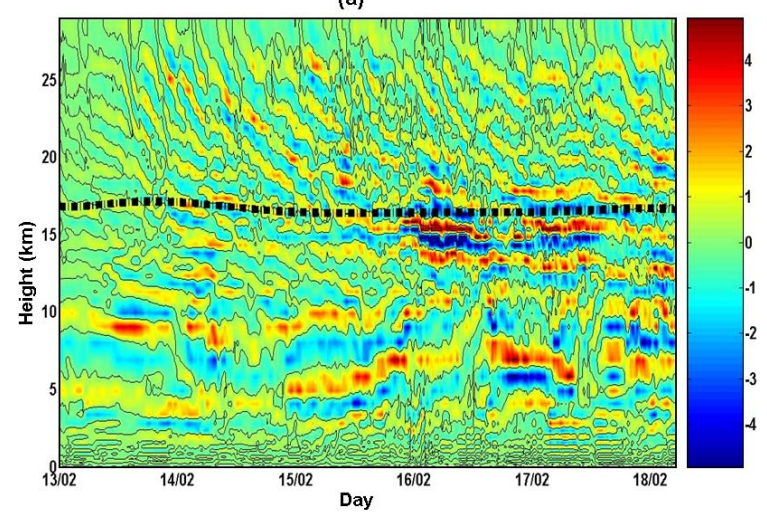

(b)

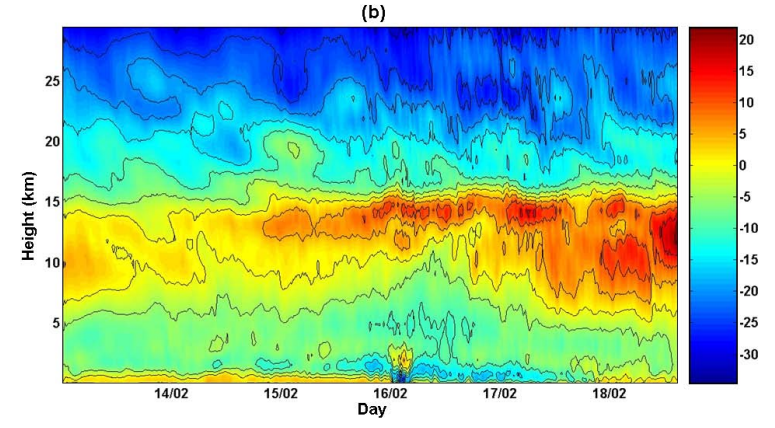

(c)

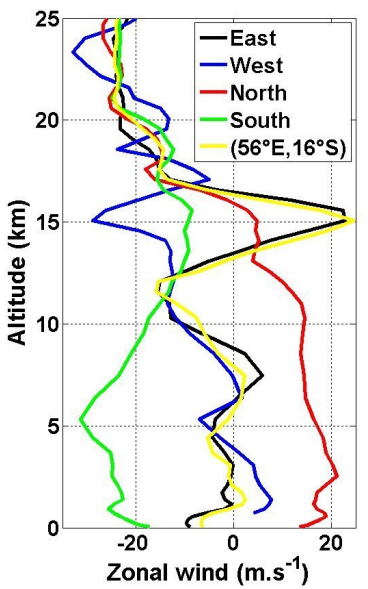

Fig. 9. (a) $10 \mathrm{~min}$ time series of vertical profile of meridional wind perturbations $\left(\mathrm{m} \mathrm{s}^{-1}\right)$ at Tromelin and (b) mean zonal wind $\left(\mathrm{m} \mathrm{s}^{-1}\right)$ at Gillot from 13 February (00:00 UTC) to 18 February 2008 (12:00 UTC). The bold broken line shows the tropopause height. (c) Vertical profiles of zonal and meridional winds at $300 \mathrm{~km}$ (north, east, south and west) and east at $56^{\circ} \mathrm{E}, 16^{\circ} \mathrm{S}$ off the TC centre on 16 February at 06:00 UTC.

The eye wall is characterized by strong updrafts with vertical velocity equal to $5-10 \mathrm{~m} \mathrm{~s}^{-1}$ from $1 \mathrm{~km}$ altitude up to $15 \mathrm{~km}$ altitude. Perturbations with short horizontal wavelengths $<50 \mathrm{~km}$ are embedded on the iso-theta contours close to the area of strong updrafts on the east side of the TC in the UT. Downdrafts are well observed in the TC eye, along the inner eye wall and on the east side of TC Ivan at

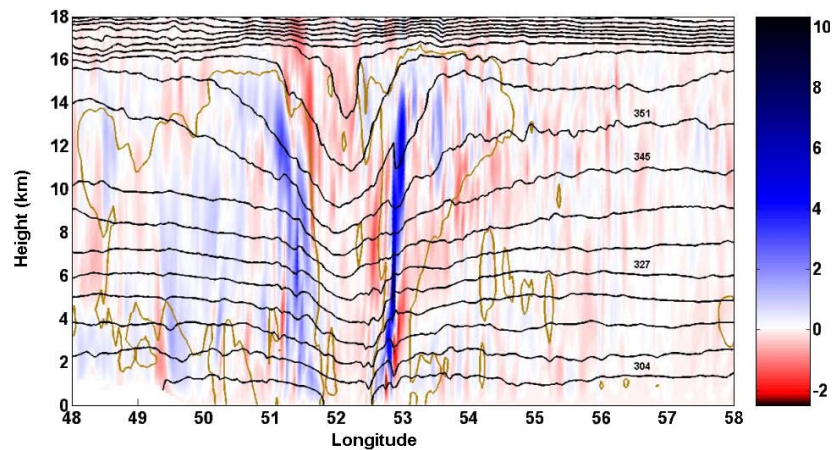

Fig. 10. Vertical cross section of vertical wind velocity $\left(\mathrm{m} \mathrm{s}^{-1}\right)$ across the storm centre at $16.1^{\circ} \mathrm{S}$ on 16 February 2008 at 12:00 UTC. The black and brown solid lines respectively indicate iso-theta contours and the boundary of cloud, which is defined by the region where the sum of mixing ratios is $>0.1 \mathrm{~g} \mathrm{~kg}^{-1}$.

altitudes of $8-12 \mathrm{~km}$. The shape of the boundary of clouds also reveals strong convection on the east side of the TC.

FFT is applied to $10 \mathrm{~min}$ time series of simulated vertical wind perturbations above the three meteorological stations (Gillot, Ivato and Tromelin) to analyse GW characteristics in the UT $(12-16 \mathrm{~km})$ and the LS $(18-25 \mathrm{~km})$ during the three stages of the TC:

- from 14 to 15 February during the development stage of the system (hereafter called P1),

- from 15 to 17 February during intensification (hereafter called P2),

- from 17 to 18 February at 12:00 UTC during landfall (hereafter called P3).

During P1, periods vary between $20 \mathrm{~min}$ and $4 \mathrm{~h}$ in the UT/LS above the three sites, with dominant high frequencies of about 20-30 min. During P2, similar periods are observed above Tromelin and Gillot. Secondary periods of $4-12 \mathrm{~h}$ are also present in the UT/LS above Ivato. In contrast, FFT spectra reveal dominant periods between 1 and $12 \mathrm{~h}$ during $\mathrm{P} 3$. Observations above Tromelin and Gillot are consistent during $\mathrm{P} 1$ and $\mathrm{P} 2$ because of their location at the same latitude.

During the intense stage of TC Ivan on 16 February 2008, vertical momentum flux increases in the UT above Tromelin $\left(0.06 \mathrm{Nm}^{-2}\right)$ and Réunion islands $\left(0.08 \mathrm{Nm}^{-2}\right)$.

Longitudinal series of horizontal pressure perturbations are filtered by a numeric monodimensional Butterworth filter to extract dominant $\mathrm{GW}$ modes with short $(<200 \mathrm{~km})$ and medium $(200-800 \mathrm{~km}$ ) horizontal wavelengths on 16 February at 12:00 UTC at $20 \mathrm{~km}$ altitude (Fig. 11a and b). Figure 11a suggests an eastward phase propagation of the mode with $400-600 \mathrm{~km}$ horizontal wavelengths from the area of intense convection located north of the TC eye. A twodimensional FFT is applied on a greyscale image of pressure perturbations at the TC area (Pratt, 2001). The bidimensional 


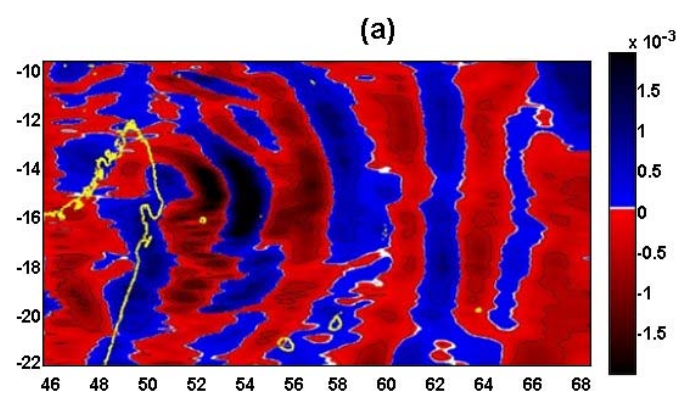

(b)

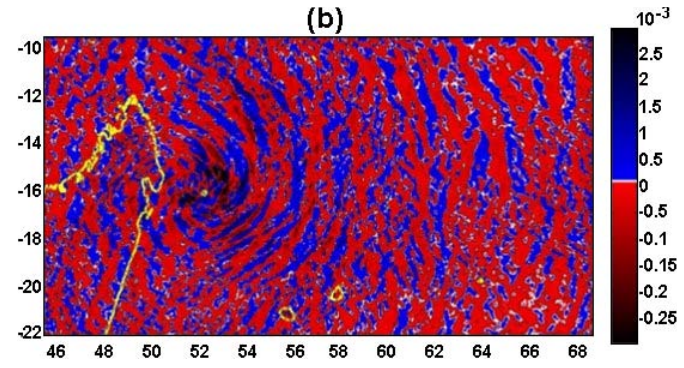

(c)

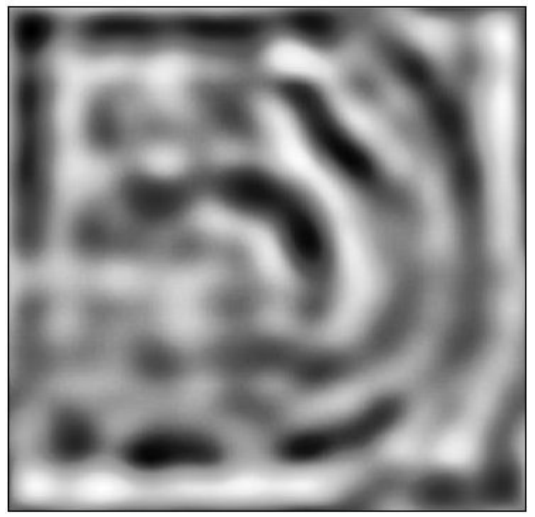

(d)

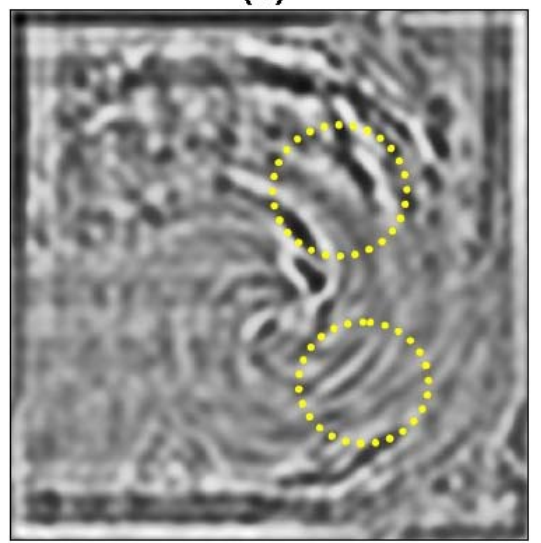

Fig. 11. Horizontal field of pressure perturbations at $20 \mathrm{~km}$ altitude on 16 February 2008 at 12:00 UTC for horizontal wavelengths between (a) 200 and $800 \mathrm{~km}$, (b) $<200 \mathrm{~km}$. A yellow dot indicates the location of the TC eye. Binary filtered images using bidimensional FFT applied on the left square regions of images (a) and (b) for modes with horizontal wavelengths of (c) $400-600 \mathrm{~km}$ and (d) $<200 \mathrm{~km}$ respectively. Yellow dotted circles show the presence of GW modes in the southeast and northeast areas. wave number space enables a multiscale analysis of the greyscale image and improves filtering from low to high frequencies. The FFT inverse provides reconstructed greyscale images for dominant modes. The contrast of the filtered greyscale image is enhanced using contrast-limited adaptive histogram equalization (Zuiderveld, 1994). Figure 11c shows evidence of semi-circular patterns for medium modes. Black pixels in the upper-left corner are attributed to processing side effects. Dominant modes of horizontal wavelengths of about $100-200 \mathrm{~km}$ are present in the southeast and northeast areas respectively (Fig. 11d). They are produced by strong convection in eastward-propagating convective bands resulting from wave number 2 vortex Rossby waves located in the northeast and southwest of the TC eye. FFT spectrum of vertical velocity provides a wide range of horizontal wavelengths between 20 and $2000 \mathrm{~km}$ with peaks at 60, 200, 500 and $1250 \mathrm{~km}$ at the latitude of TC eye in the LS. Mean values at latitudes of $9-21^{\circ} \mathrm{S}$ reveal that most of the energy of observed modes is located at the latitude of the TC eye (Fig. 12a). Large FFT amplitudes are displayed for shortscale waves $(20-80 \mathrm{~km})$ at the latitude of the TC eye and longer scale waves $(>150 \mathrm{~km})$ above the TC area $\left(9-21^{\circ} \mathrm{S}\right)$. Waves with 400-500 km horizontal wavelength are dominant above the TC basin during TC intensification. Figure 12b supports findings that observed modes are mainly located near the latitudes of the TC eye. Long-scale modes have large latitudinal extension. Figure 12c provides longitudehorizontal wavelength distribution derived from CWT of vertical velocity at the latitude of the TC eye. It also supports the presence of modes with horizontal wavelengths $<2000 \mathrm{~km}$ associated with TC Ivan. Energy of modes with $20-80 \mathrm{~km}$ horizontal wavelengths is confined to longitudes of $50-55^{\circ} \mathrm{E}$ near the TC eye and locally dominant. It peaks at $64 \mathrm{~km}$ horizontal wavelength at the location of the TC eye. Indeed, highfrequency GWs with horizontal wavelengths $15-50 \mathrm{~km}$ and periods of about 15-20 min, observed during P1 and P2, are expected in the vicinity of strong convection (Dewan et al., 1998; Lane and Reeder, 2001).

Energy of medium-scale modes $(100-800 \mathrm{~km})$ with peaks at 150 and $500 \mathrm{~km}$ horizontal wavelengths are secondary dominant. It is mainly observed east of the TC, while energy of longer modes $(1250 \mathrm{~km})$ has a horizontal extension west of the TC. Globally, a longitudinal extension east of the TC is displayed for observed modes. Thus this last figure complements that of ECMWF outputs, especially for modes with horizontal wavelengths of $32-350 \mathrm{~km}$.

Similar modes are also observed in the horizontal wind, potential temperature and pressure. On 16 February at 12:00 UTC, horizontal wavelengths of GWs range between 40 and $60 \mathrm{~km}$ and between 300 and $500 \mathrm{~km}$ with dominant periods of 12 and $12-58 \mathrm{~h}$ (frequencies of $1.4 \times 10^{-3} \mathrm{~s}^{-1}$ and $\left.1.39 \times 10^{-4} \mathrm{~s}^{-1}-3.5 \times 10^{-5} \mathrm{~s}^{-1}\right)$. The linear $\mathrm{GW}$ dispersion relationship provides vertical wavelengths of about 1.5 and $3.3 \mathrm{~km}$ respectively. 


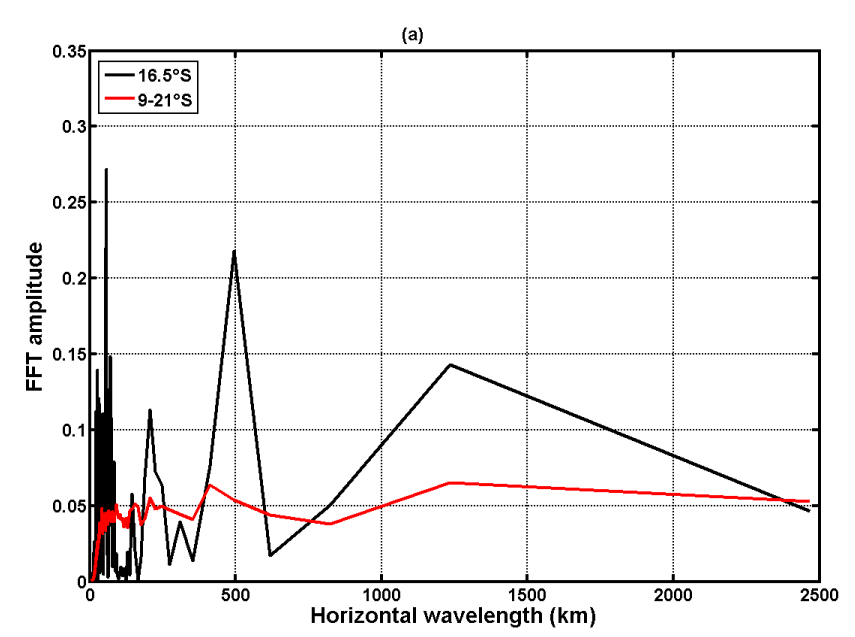

(b)

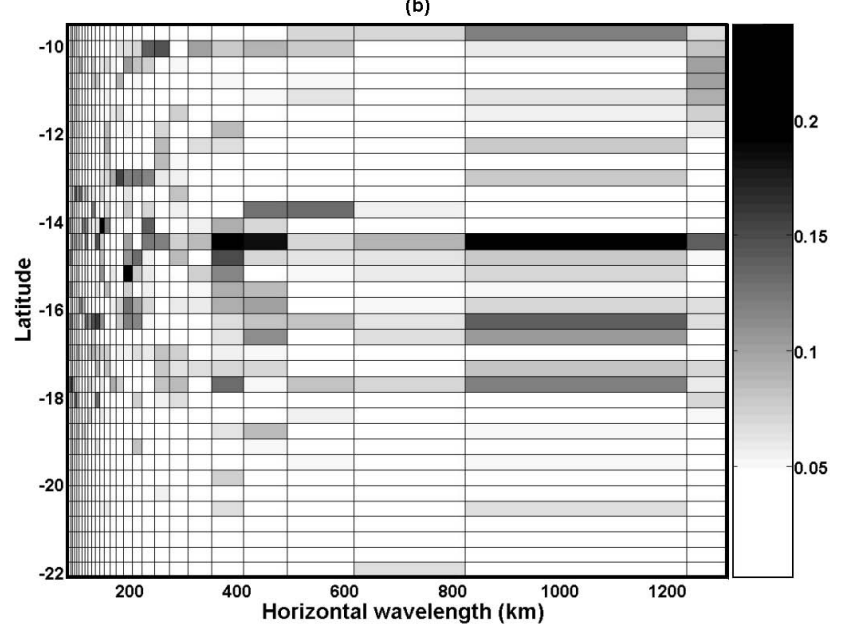

(c)

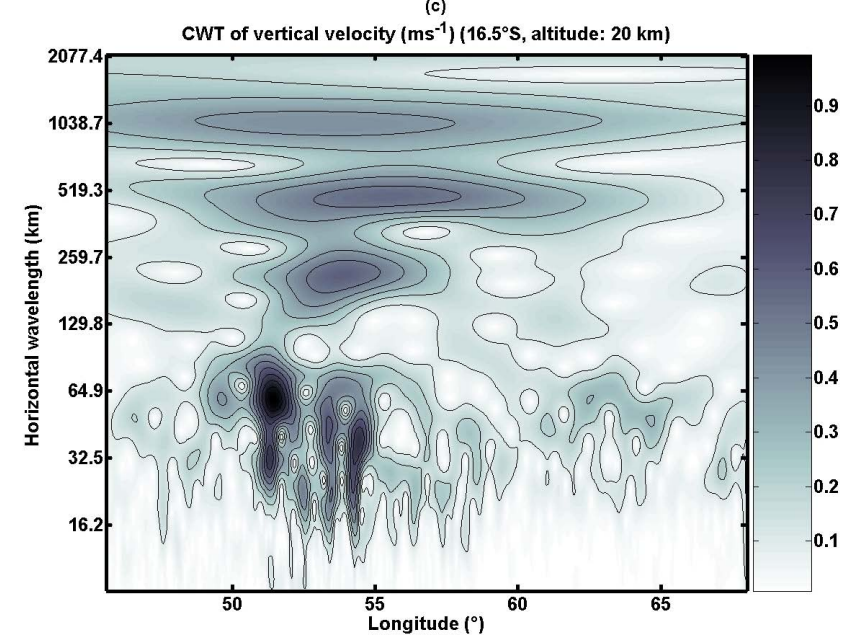

Fig. 12. Fast Fourier transform of vertical velocity $\left(\mathrm{m} \mathrm{s}^{-1}\right)$ (a) at latitudes of $16.5^{\circ} \mathrm{S}$ and $9-21^{\circ} \mathrm{S}$ and (b) as a function of latitude at the altitude of $20 \mathrm{~km}$ on 16 February 2008 at 12:00 UTC. (c) Morlet continuous wavelet transform of vertical velocity at $16.5^{\circ} \mathrm{S}$.

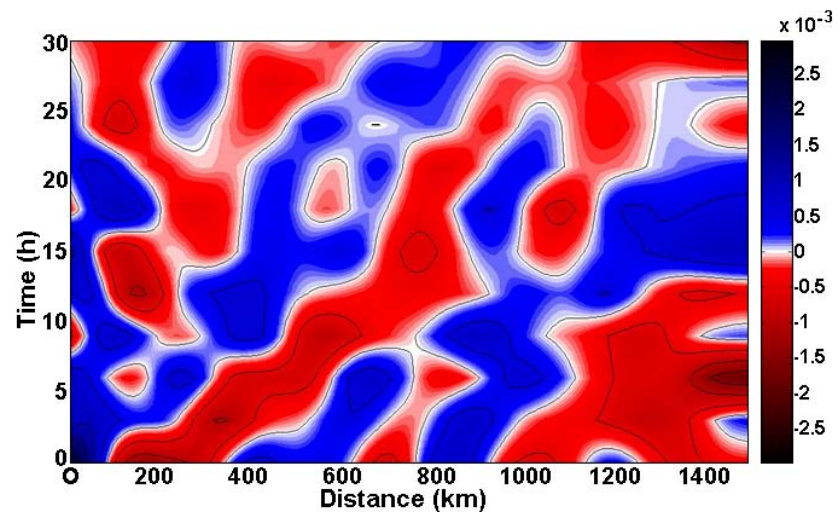

Fig. 13. Hovmöller diagram of longitudinal pressure perturbation at $16^{\circ} \mathrm{S}$ from 16 February 2008 at 12:00 UTC to 17 February at 18:00 UTC at $20 \mathrm{~km}$.

Vertical profiles of zonal and meridional wind perturbations are examined at the location where GWs are observed on 16 February at 12:00 UTC (Fig. 11c, d). They show evidence of a simulated vertical wavelength of $2.5-3 \mathrm{~km}$ for modes of horizontal wavelengths of 300-600 km, previously observed in Fig. 9a. In addition perturbations only suggest that modes of $40-60 \mathrm{~km}$ horizontal wavelengths have vertical wavelengths $<2 \mathrm{~km}$ because of the $500 \mathrm{~m}$ vertical resolution in the LS. Simulated wavelengths are in agreement with estimated vertical wavelengths.

Figure 13 displays a Hovmöller diagram of longitudinal pressure perturbations for modes with horizontal wavelengths between 200 and $800 \mathrm{~km}$ from 16 February at 12:00 UTC to 17 February at 18:00 UTC at a latitude of $16^{\circ} \mathrm{S}$. It reveals an eastward propagation of about $8-11 \mathrm{~m} \mathrm{~s}^{-1}$ for medium modes in the LS.

Finally, Meso-NH provides a realistic detailed description of low-frequency GWs in terms of perturbation amplitudes and phase relations.

\section{Characteristics of TC rainbands}

Spiral rainbands may produce severe rainfall outside the eye wall and play an important role in changing the dynamic structure of a TC, especially in the formation of concentric eye walls (Wang and Wu, 2004; Hence and Houze, 2012). They can be triggered both by inertia GWs (Willoughby, 1978) and vortex Rossby waves (Montgomery and Kallenbach 1997). Mechanisms of spontaneous emission of spiral IG waves and impacts on the angular momentum of TCs through outward spiral rainbands are discussed in Chow et al. (2002), Chow and Chan (2003) and Schecter (2008). Thus, recent studies demonstrate that wave-induced spiral rainbands affect $\mathrm{TC}$ intensity.

Here, characteristics of simulated TC rainbands are analysed from 15 February at 21:00 UTC to 17 February at 21:00 UTC. On 15 February at 21:00 UTC, a symmetry in 

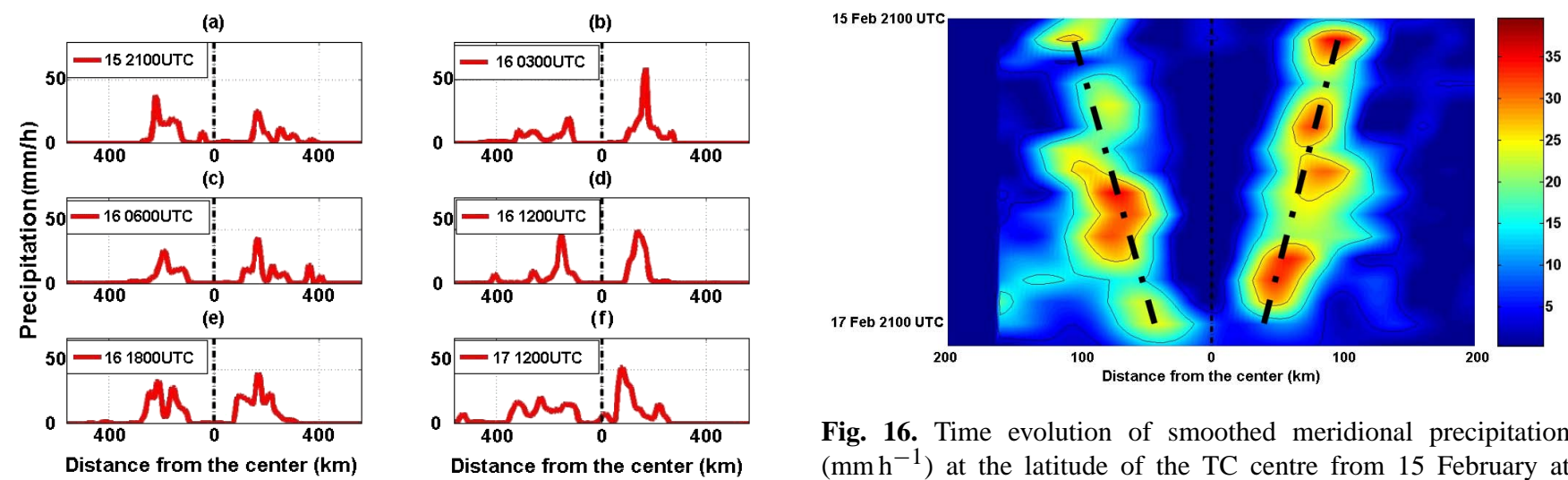

Fig. 16. Time evolution of smoothed meridional precipitation $\left(\mathrm{mm} \mathrm{h}^{-1}\right)$ at the latitude of the TC centre from 15 February at 21:00 UTC to 17 February at 21:00 UTC. The TC centre is used as origin for distance. Dotted broken lines indicate eye contraction.

14. Longitudinal precipitation cross section at the centre TC Ivan on 15 February 2008 at 21:00 UTC (a); 16 February at 03:00 UTC (b), 06:00 UTC (c), 12:00 UTC (d), and 18:00 UTC (e); and 17 February at 12:00 UTC (f).

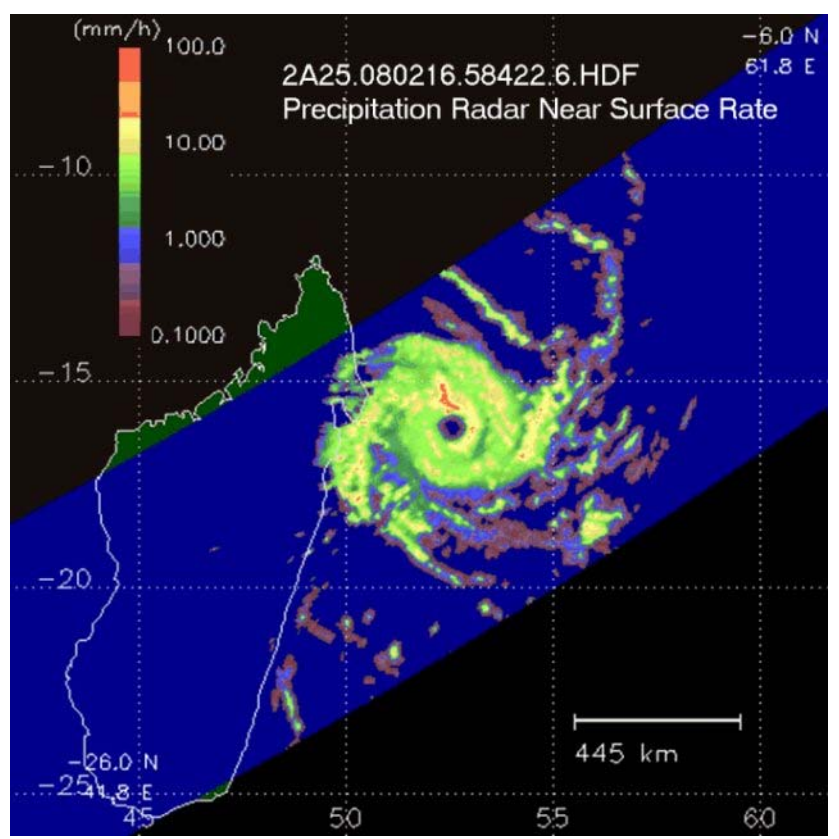

Fig. 15. TRMM precipitation radar near-surface precipitation rate from 06:05:43 to 07:38:06 UTC on 16 February 2008.

TC rainbands is observed between east and west sides of the TC. The east-west (E-W) intensity ratio of maximum precipitation (IRMP) is about 0.7 (Fig. 14a). The eye is observed to be $132 \mathrm{~km}$ in size. On 16 February at 03:00 UTC, intensification of the eye wall of TC Ivan is accompanied by an intensification of precipitation on the east side of the system. E-W IRMP and eye size are estimated to be about 2.8 and $100 \mathrm{~km}$ respectively (Fig.14b). On 16 February at 06:00 UTC, an asymmetry in TC rainbands is observed (Fig. 14c). The EW IRMP decreases to about 1.4. Short rainbands of about $16 \mathrm{~km}$ wavelength appear on the eastern side of the TC. 


\section{Discussion and conclusions}

Characteristics of GWs were examined in the UT/LS during the evolution of TC Ivan (2008) in the SWIO. Dominant low-frequency GWs (periods of 4.6-13 h) with horizontal and vertical wavelengths of $80-400 \mathrm{~km}$ and $0.7-3 \mathrm{~km}$, respectively, were retrieved from radiosonde and GPS RO measurements. In particular, an inertia GW with vertical wavelength of $2-3 \mathrm{~km}$, horizontal wavelength of $\sim 400 \mathrm{~km}$ and a period of $13 \mathrm{~h}$ is observed to be dominant and more intense east of TC Ivan in the LS over the SWIO during TC intensification. This inertia GW propagates eastward in the LS. Because observational filtering and altitude ranges, the analysis is focused on modes with short vertical wavelengths $<4$ $5 \mathrm{~km}$ and periods $>2 \mathrm{~h}$.

ECMWF analyses provided insight into the spectrum of low-frequency convective GWs with horizontal wavelengths between 350 and $2000 \mathrm{~km}$ and vertical wavelengths $>2 \mathrm{~km}$ in the LS. They revealed that some waves are closely linked to TC Ivan. In particular, a large continuous spectrum of GWs with horizontal wavelengths between 350 and $1000 \mathrm{~km}$ is observed east of the TC eye. East of the TC, a dominant mode of horizontal wavelength of $600 \mathrm{~km}$ and a $12.8 \mathrm{~h}$ period propagated eastward favoured by the westward background wind in the LS. ECMWF analyses also indicated the presence of GWs with long horizontal wavelengths of $1400-1700 \mathrm{~km}$ west of the TC with estimated periods of 1-2 days.

Meso-NH simulations provided detailed information about the activity and characteristics of TC-related GWs during the development stage, intensification and landfall. Model outputs revealed a larger spectrum with high- and low-frequency GWs (periods of 20 min-2 days), horizontal wavelengths ranged between 32 and $2000 \mathrm{~km}$ and short vertical wavelengths of 1.5 and $3.3 \mathrm{~km}$. High-frequency modes produced by localized strong convection are dominant near the TC eye during TC intensification. In addition the model highlights intensity and spatial extension of other dominant mesoscale GWs. In particular, Meso-NH provided a good detailed description of dominant inertia GW with $300-600 \mathrm{~km}$ horizontal wavelengths and $3 \mathrm{~km}$ vertical wavelength during TC intensification. Strong convection resulting from wave number 1 and wave number 2 vortex Rossby waves was suggested as the source of GWs with dominant horizontal wavelengths of $300-600 \mathrm{~km}$ and $100-200 \mathrm{~km}$ respectively.

Thus, observation and model outputs supported the presence of a dominant quasi-inertia GW with horizontal and vertical wavelengths of $400-800 \mathrm{~km}$ and $1.5-3.5 \mathrm{~km}$ propagating eastward east of TC Ivan. This was closely linked to TC intensity with largest amplitudes during TC intensification.

Results are consistent with previous observational studies on characteristics of TC-related GWs (Chane Ming et al., 2002, 2010) and link between GW energy density and TC activity in the UT/LS (Ibrahim et al., 2010). Chane Ming et al. (2010) also detected dominant eastward-propagating modes with a horizontal wavelength of about $500 \mathrm{~km}$ in the
UT/LS during intense TC Dina (2002) in the SWIO and TC Faxai (2001) in north west Pacific Ocean with prevailing westward wind between altitudes of 10 and $22 \mathrm{~km}$ and eastward QBO above. An increase in total energy density of about $30 \%$ of the climatological energy density in austral summer was estimated in the LS above Tromelin during TC Dina. From numerical simulations with a horizontal grid size of $27 \mathrm{~km}$, Kim et al. $(2005,2009)$ analysed low-frequency GWs with medium horizontal wavelengths of $300-600 \mathrm{~km}$, a vertical wavelength of $3-11 \mathrm{~km}$ and a period of 6-11 h during the category 4 TCs Rusa (2002) and Ewiniar (2006) in the LS. Convection in the TC-generated cloud bands was suggested to be a major source of GWs during TC Rusa. Dominant eastward-propagating stratospheric waves were observed during the mature stage of TC Ewiniar. In contrast, Kuester et al. (2008) simulated high-frequency GWs with horizontal wavelengths of $15-300 \mathrm{~km}$, vertical wavelengths of 4-8 km and intrinsic periods of 20-100 min above the category 2 TC Humberto (2001) with nested horizontal grids of 27, 9 and $3 \mathrm{~km}$. With similar grids, Kim and Chun (2010) examined eastward-propagating GWs with horizontal wavelengths of $10-100 \mathrm{~km}$ and periods less than $2 \mathrm{~h}$ produced by the category 5 TC Saomai (2006). Waves with horizontal wavelengths $>80 \mathrm{~km}$ and periods $>1 \mathrm{~h}$ are found to be the dominant contribution to the momentum flux. More recently, using a large domain with a $27 \mathrm{~km}$ horizontal resolution, Chen et al. (2012) numerically investigated eastward-propagating GWs with long horizontal scales of about $1000 \mathrm{~km}$ generated by TC Matsa (2005) in the LS. Vertical resolution of previous simulations was about $500 \mathrm{~m}$ in the UT/LS.

Results also supported that some GWs related to a TC could be filtered out by the background wind and contribute locally to the QBO forcing in the LS. Strong GW activity was also observed during landfall accompanied with the enhancement of eastward wind in the middle troposphere. In addition characteristics of TC rainbands revealed intensification of TC eye wall with strong precipitation on the east side of TC Ivan during intensification. Meso-NH simulation also revealed high-frequency GW-related TC clouds in the troposphere on February 16 and a symmetrical eye contraction cycle during TC intensification and landfall.

Previously, asymmetries in surface friction caused by vortex translation were suggested to produce a wave number 1 asymmetry in convergence (Shapiro, 1983). Asymmetric forcing has also been studied as a possibly important intensification mechanism. Eye wall convection can on the one hand be enhanced and shifted inward by inflow associated with the vortex Rossby waves in the lower troposphere, while on the other hand it is suppressed and shifted outward by outflow (Wang, 2002a). Asymmetries can transport energy to the outside of the eye wall due to the nature of the vortex Rossby waves (Montgomery and Kalenbach, 1997). Eye wall asymmetries interact with the mean vortex through eddy momentum fluxes and partially extract their kinetic energy 
from the mean vortex, leading to weakening of the mean tangential and radial winds (Houze et al., 2006). If TC asymmetries become sufficiently strong, then air with high values of potential vorticity and equivalent potential temperature is mixed outward and causes the weakening of the warm core aloft and the increase of central pressure (Frank and Ritchie, 2001). Radial maximum wind can also be accelerated during the intensification stage and produce an eye wall contraction (Houze et al., 2006), which was observed in the present simulation. It was also revealed that the environmental shear induced by land-sea contrast could produce highly asymmetric structures in landfalling TC responsible for the distribution of the strongest wind and the heaviest rainfall (Chen and Yau, 2003). An asymmetry first occurs at the top of the vortex and propagates to the surface. Rainfall is generally observed to have a maximum ahead of the TC centre, which indicates the importance of surface friction induced by low-level convergence. Thus observations and numerical simulations have suggested vortex Rossby waves to be related to changes in the structure and intensity of TCs (Wang, 2002b). In addition, outward propagation of wave number 1 Rossby waves is believed to initiate inner spiral rainbands. During storm intensity change, shearing deformation can stretch vorticity into filaments that spiral toward the centre of the TC (Houze et al., 2006). In addition, Chow et al (2002) show that fluctuation of the PV distribution in the TC core region can act as a source, generating GWs that produce banded structures and the moving spiral rainbands. Chen et al. (2006) showed that during austral summer, when TCs are active in the Southern Hemisphere, vertical wind shear is mostly weak and moderate $\left(<15 \mathrm{~m} \mathrm{~s}^{-1}\right)$ and that TCs display the largest asymmetries. In our study the contrast in wind shear enhanced by land-sea contrast is suggested to be responsible for the observed wave number 1 asymmetry during the intensification stage just before landfall of TC Ivan.

In conclusion, the French research model Meso-NH proved to be a useful numerical tool to explore the large continuous spectrum of TC-related GWs in the UT/LS in relation to realistic TC dynamics. Further studies should include detailed description of GW sources, GW anisotropic propagation and GW effects on the rainband characteristics and the background wind.

Acknowledgements. We are indebted to the Meso-NH team at Météo-France and Laboratoire d'Aérologie for the source code and assistance. The Meso-NH model was run on supercomputers of the University of La Réunion and Météo-France. We also thank the editor Timothy J. Dunkerton and the anonymous reviewers for providing constructive comments. This work was financially supported by La Région Réunion and the European Union, the Fondation MAIF (PRECYP project) and by ANR (StraDyVariUS project).

Edited by: T. J. Dunkerton

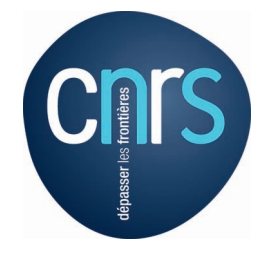

The publication of this article is financed by CNRS-INSU.

\section{References}

Alexander, M. J.: Parameterization of Physical Processes: Gravity wave momentum fluxes, Encyclopedia of the Atmospheric Sciences, Academic/Elsevier, London, 1699-1705, 2003.

Alexander, M. J. and Barnet, C.: Using satellite observations to constrain parameterizations of gravity wave effects for global models, J. Atmos. Sci., 64, 1652-1665, 2007.

Alexander, M. J., Geller, M., McLandress, C., Polavarapu, S., Preusse, P., Sassi, F., Sato, K., Eckermann, S., Ern, M., Hertzog, A., Kawatani, Y., Pulido, M., Shaw, T., Sigmond, M., Vincent, R., and Watanabe, S.: Recent developments in gravity wave effects in climate models, and the global distribution of gravity wave momentum flux from observations and models, Q. J. Roy. Meteorol. Soc., 136, 1103-1124, 2010.

Alexander, S. P., Tsuda, T., Kawatani, Y., and Takahashi, M.: Global distribution of atmospheric waves in the equatorial upper troposphere and lower stratosphere: COSMIC observations of wave mean flow interactions, J. Geophys. Res., 113, D24115, doi:10.1029/2008JD010039, 2008.

Anthes, R. A.: Exploring Earth's atmosphere with radio occultation: contributions to weather, climate and space weather, Atmos. Meas. Tech., 4, 1077-1103, doi:10.5194/amt-4-1077-2011, 2011.

Baldwin, M. P., Gray, L. J., Dunkerton, T. J., Hamilton, K., Haynes, P. H., Randel, W. J., Holton, J. R., Alexander, M. J., Hirota, I., Horinouchi, T., Jones, D. B. A., Kinnersley, J. S., Marquardt, C., Sato, K., and Takahashi, M.: The Quasi-Biennial Oscillation, Rev. Geophys., 39, 179-229, doi:10.1029/1999RG000073, 2001.

Bechtold, P., Bazile, E., Guichard, F., Mascart, P., and Richard, E.: A mass flux convection scheme for regional and global models, Q. J. Roy. Meteorol. Soc., 127, 869-886, 2001.

Chaboureau, J.-P., Cammas, J.-P., Mascart, P., Pinty, J.-P., Claud, C., Roca, R., and Morcrette, J.-J.: Evaluation of a cloud system life-cycle simulated by Meso-NH during FASTEX using METEOSAT radiances and TOVS-3I cloud retrievals, Q. J. Roy. Meteorol. Soc., 126, 1735-1750, 2000.

Chane Ming, F., Molinaro, F., and Leveau, J.: Wavelet techniques applied to lidar signal in the analysis of the middle atmosphere dynamics, Appl. Sig. Process., 6, 95-106, 1999.

Chane-Ming, F., Roff, G., Robert, L., and Leveau, J.: Gravity waves characteristic over Tromelin Island during the passage of cyclone Hudah, Geophys. Res. Lett., 29, 18-1-18-4, doi:10.1029/2003JD003489, 2002.

Chane-Ming, F., Faduilhe, D., and Leveau, J.: Latitudinal and seasonal variability of gravity energy in the South-West Indian Ocean, Ann. Geophys., 25, 2479-2485, doi:10.5194/angeo-252479-2007, 2007.

Chane-Ming, F., Chen, Z., and Roux, F.: Analysis of gravity-waves produced by intense tropical cyclones, Ann. Geophys., 28, 531547, doi:10.5194/angeo-28-531-2010, 2010. 
Chen, D., Chen, Z. Y., and Lü, D. R.: Simulation of the stratospheric gravity waves generated by the Typhoon Matsa in 2005, Sci. China Earth Sci., 55, 602-610, doi:10.1007/s11430-011-4303-1, 2012.

Chen, S., Knaff, J. A., and Marks, F. D.: Effects of vertical wind shear and storm motion on tropical cyclone rainfall asymmetries deduced from TRMM, Mon. Weather Rev., 134, 3190-3208, 2006.

Chen, Y., and Yau, M. K.: Asymmetric structures in a simulated landfall hurricane, J. Atmos. Phys., 60, 2294-2312, 2003.

Chow, K. C. and Chan, K. L.: Angular momentum transports by moving spiral waves, J. Atmos. Sci., 60, 2004-2009, 2003.

Chow, K. C., Chan, K. L., and Lau, A. K. H.: Generation of moving spiral bands in tropical cyclones, J. Atmos. Sci., 59, 2930-2950, 2002.

Clark, T. L., Hauf, T., and Kuettner, J. P.: Convectively forced internal gravity waves: Results from two-dimensional numerical experiments, Q. J. Roy. Meteorol. Soc., 112, 899-925, 1986.

Cuxart, J., Bougeault, P., and Redelsperger, J.-L.: A turbulence scheme for mesoscale and large-eddy simulations, Q. J. Roy. Meteorol. Soc., 126, 1-30, 2000.

Das, S. S., Uma, K. N., and Das, S. K.: MST radar observations of short-period gravity wave during overhead tropical cyclone, Radio Sci., 47, RS2019, doi:10.1029/2011RS004840, 2012.

Dewan, E. M., Picard, R. H., O’Neil, R. R., Gardiner, H. A., Gibson, J., Mill, J. D., Richards, E., Kendra, M., and Gallery, W. O.: MSX satellite observations of thunderstorm-generated gravity waves in mid-wave infrared images of the upper stratosphere, Geophys. Res. Lett., 25, 939-942, 1998.

Dhaka, S. K., Takahashi, M., Shibagaki, Y., Yamanaka, M. D., and Fukao, S.: Gravity wave generation in the lower stratosphere due to passage of the Typhoon 9426 (Orchid) observed by the MU radar at Shigaraki $\left(34.85^{\circ} \mathrm{N}, 136.10^{\circ} \mathrm{E}\right)$, J. Geophys. Res., 108, 4595, doi:10.1029/2003JD003489, 2003.

Dunkerton, T. J.: Theory of the mesopause semiannual oscillation, J. Atmos. Sci., 39, 2681-2690, 1982.

Ern, M. and Preusse, P.: Gravity wave momentum flux spectra observed from satellite in the summertime subtropics: Implications for global modeling, Geophys. Res. Lett., 39, L15810, doi:10.1029/2012GL052659, 2012.

Fovell, R., Durran, D., and Holton, J. R.: Numerical simulations of convectively generated stratospheric gravity waves, J. Atmos. Sci., 49, 1427-1442, 1992.

Frank, W. M. and Ritchie, E. A.: Effects of vertical wind shear on the intensity and structure of numerically simulated hurricanes, Mon. Weather Rev., 129, 2249-2269, 2001.

Fritts, D. C. and Alexander, M. J.: Gravity wave dynamics and effects in the middle atmosphere, Rev. Geophys., 41, 1003, doi:10.1029/2001RG000106, 2003.

Gill, A. E.: Atmosphere-Ocean Dynamics, Academic Press, Inc., New York, USA, 662 pp., 1982.

Gregory, D., Morcrette, J.-J., Jakob, C., Beljaars, A. C. M., and Stockdale, T.: Revision of convection, radiation and cloud schemes in the ECMWF Integrated Forecasting System, Q. J. Roy. Meteorol. Soc., 126, 1685-1710, 2000.

Healy, S. B.: Operational assimilation of GPS radio occultation measurements at ECMWF, available online at: http:// www.ecmwf.int/publications/newsletters/pdf/111.pdf, ECMWF Newsletter, 111, 6-11, 2007.
Healy, S. B. and Thepaut, J. N.: Assimilation experiments with CHAMP GPS radio occultation measurements, Q. J. Roy. Meteorol. Soc., 132, 605-623, doi:10.1256/qj.04.182, 2006.

Hence, D. A. and Houze, R. A.: Vertical structure of tropical cyclone rainbands as seen by the TRMM precipitation radar, J. Atmos. Sci., 69, 2644-2661, 2012.

Hendricks, E. A., Schubert, W. H., Fulton, S. R., and McNoldy, B. D.: Spontaneous-adjustment emission of inertia-gravity waves by unsteady vortical motion in the hurricane core, Q. J. Roy. Meteor. Soc., 136, 537-548, 2008.

Hendricks, E. A., McNoldy, B. D., and Schubert, W. H.: Observed inner core structural variability in hurricane Dolly (2008), Mon. Weather Rev., 140, 4066-4077, 2012.

Horinouchi, T., Nakamura, T., and Kosaka, J.: Convectively generated mesoscale gravity waves simulated throughout the middle atmosphere, Geophys. Res. Lett., 29, 2007, doi:10.1029/2002GL016069, 2002.

Houze, R. A.: Clouds in tropical cyclones, Mon. Weather Rev., 138, 293-344, 2010.

Houze, R. A., Cetrone, J., Brodzik, S. R., Chen, S. S., Zhao, W., Lee, W.-C., Moore, J. A., Stossmeister, G. J., Bell, M. M., and Rogers, F. F.: The hurricane rainband and intensity change experiment: Observations and modeling of hurricanes Katrina, Ophelia, and Rita, B. Am. Meteor. Soc., 87, 1503-1521, 2006.

Huang, C.-Y., Kuo, Y.-H., Chen, S.-Y., Terng, C.-T., Chien, F.-C., Lin, P.-L., Kueh, M.-T., Chen, S.-H., Yang, M.-J., Wang, C.-J., and Rao, A. S. K. A. P.: Impact of GPS radio occultation data assimilation on regional weather predictions, GPS Solutions, 14, 35-49, doi:10.1007/s 10291-009-0144-1, 2010.

Ibrahim, C., Chane Ming, F., Barthe, C., and Kuleshov, Y: Diagnosis of tropical cyclone activity through gravity wave energy density in the South West Indian Ocean, Geophys. Res. Lett., 37, L09807, doi:10.1029/2010GL042938, 2010.

Jolivet S., Chane Ming, F., Barbary, D., and Roux, F.: A numerical study of orographic forcing on TC Dina (2002) in South West Indian Ocean, Ann. Geophys., 31, 107-125, doi:10.5194/angeo31-107-2013, 2013.

Kain, J. S. and Fritsch, J. M.: A One-dimensional entraining/detraining plume model and its application in convective parameterization, J. Atmos. Sci., 47, 2784-2802, 1990.

Kawatani, Y., Watanabe, S., Sato, K., Dunkerton, T. J., Miyahara, S., and Takahashi, M.: The roles of equatorial trapped waves and internal inertia-gravity waves in driving the Quasi-Biennial oscillation. Part I: Zonal mean wave forcing, J. Atmos. Sci., 67, 963-980, doi:10.1175/2009JAS3222.1, 2010.

Kim, S.-Y. and Chun, H.-Y.: Stratospheric gravity waves generated by Typhoon Saomai (2006): numerical modeling in a moving frame following the typhoon, J. Atmos. Sci., 67, 3617-3636, doi:10.1175/2010JAS3374.1, 2010.

Kim, S.-Y. and Chun, H.-Y.: Impact of typhoon-generated gravity waves in the typhoon development, Geophys. Res. Lett., 38, L01806, doi:10.1029/2010GL045719, 719, 2011.

Kim, S.-Y., Chun, H.-Y., and Baik, J.-J.: A numerical study of gravity waves induced by convection associated with Typhoon Rusa, Geophys. Res. Lett., 32, L24816, doi:10.1029/2005GL024662, 2005.

Kim, S.-Y., Chun, H.-Y., and Wu, D. L.: A study on stratospheric gravity waves generated by Typhoon Ewiniar: numerical simula- 
tions and satellite observations, J. Geophys. Res., 114, D22104, doi:10.1029/2009JD011971, 2009.

Kim, Y.-J. and Chun, H.-Y.: A computationally efficient non stationary convective gravity-wave drag parameterization for global atmospheric prediction systems, Geophys. Res. Lett., 32, L22805, doi:10.1029/2005GL024572, 2005.

Kim, Y.-J., Eckermann, S. E., and Chun, H.-Y.: An overview of the past, present and future of gravity-wave drag parameterization for numerical climate and weather prediction models, Atmos. Ocean, 41, 65-98, 2003.

Klemp, J. B.: Advances in the WRF model for convection resolving forecasting, Adv. Geosci., 7, 25-29, 2006, http://www.adv-geosci.net/7/25/2006/.

Kuester, M. A., Alexander, M. J., and Ray, E. A.: A model study of gravity waves over Hurricane Humberto (2001), J. Atmos. Sci., 65, 3231-3246, 2008.

Kunii M., Seko, H., Ueno, M., Shoji, Y., and Tsuda, T.: Impact of Assimilation of GPS radio occultation refractivity on the forecast of Typhoon Usagi in 2007, J. Meteor. Soc. Jpn., 90, 255-273, doi:10.2151/jmsj.2012-207, 2012.

Lac, C., Lafore, J.-P., and Redelsperger, J.-L.: Role of gravity waves in triggering deep convection during TOGA COARE, J. Atmos. Sci., 59, 1293-1316, 2002.

Lafore, J. P., Stein, J., Asencio, N., Bougeault, P., Ducrocq, V., Duron, J., Fischer, C., Hereil, P., Mascart, P., Pinty, J.-P., Redelsperger, J.-L., Richard, E., and Vila-Guerau de Arellano, J.: The Meso-NH atmospheric simulation system. Part I: Adiabatic formulation and control simulations, Ann. Geophys., 16, 90-109, doi:10.1007/s00585-997-0090-6, 1998.

Lane, T. P. and Knievel, J. C.: Some effects of model resolution on simulated gravity waves generated by deep, mesoscale convection, J. Atmos. Sci., 62, 3408-3419, doi:10.1175/JAS, 2005.

Lane, T. P. and Reeder, M. J.: Modelling the generation of gravity waves by a maritime continent thunderstorm, Q. J. Roy. Meteor. Soc., 127, 2705-2724, 2001.

Leclaire De Bellevue, J., Baray, J. L.,Baldy, S., Ancellet, G., Diab, R., and Ravetta, F.: Simulations of stratospheric to tropospheric transport during the tropical cyclone Marlene event, Atmos. Environ., 41, 6510, doi:10.1016/j.atmosenv.2007.04.040, 2007.

Lin, C. Y., Hsu, H. M., Sheng, Y. F., Kuo, C. H., and Liou, Y. A.: Mesoscale processes for super heavy rainfall of Typhoon Morakot (2009) over southern Taiwan, Atmos. Chem. Phys. 11, 345-361, doi:10.5194/acp-11-345-2011, 2011.

Liou, Y.-A., Pavelyev, A. G., Huang, C.-Y., Igarashi, K., Hocke, K., and Yan, S.-K.: Analytic method for observation of the gravity waves using radio occultation data, Geophys. Res. Lett., 30, 2021, doi:10.1029/2003GL017818, 2003.

Liou, Y.-A., Pavelyev, A. G., Wicker, J., Liu, S. F., Pavelyev, A. A., Schmidt, T., and Igarashi, K.: Application of GPS radio occultation method for observation of the internal waves in the atmosphere, J. Geophys. Res., 111, D06104, doi:10.1029/2005JD005823, 2006.

Liou, Y.-A., Pavelyev, A. G., Matyugov, S. S., Yakovlev, O. I., and Wickert, J.: Radio Occultation Method for Remote Sensing of the Atmosphere and Ionosphere, INTECH, Vukovar, Croatia, 170 pp., 2010.

Liu, H., Anderson, J., and Kuo, Y.-H.: Improved analyses and forecasts of Hurricane Ernesto's genesis using radio occultation data in an ensemble filter assimilation system, Mon. Weather Rev., 140, 151-166, doi:10.1175/MWR-D-11-00024.1, 2012.

Liu, Y., Zhang, D.-L., and Yau, M. K.: A Multiscale Numerical Study of Hurricane Andrew (1992). Part II: Kinematics and Inner-Core Structures, Mon. Weather Rev., 127, 2597-2616, 1999.

Marks, F. D., Houze, R. A., and Gamache, J. F.: Dual-Aircraft Investigation of the inner core of Hurricane Norbert. Part I: Kinematic structure, J. Atmos. Sci., 49, 919-942, 1992.

Montgomery, M. T. and Kallenbach, R. J.: A theory for vortex Rossby-waves and its application to spiral bands and intensity changes in hurricanes, Q. J. Roy. Meteor. Soc., 123, 435-465, 1997.

Montroty, R., Rabier, F., Westrelin, S., Faure, G., and Viltard, N.: Impact of wind bogus and cloud and rain affected SSM/I data on tropical cyclones analyses and forecasts, Q. J. Roy. Meteor. Soc., 134, 1673-1699, 2008.

Niranjan Kumar, K., Ramkumar, T. K., and Krishnaiah, M.: MST Radar observation of inertia-gravity waves generated from tropical cyclones, J. Atmos. Sol. Terr. Phys., 73, 1890-1906, 2011.

Nuissier, O., Rogers, R. F., and Roux, F.: A numerical simulation of Hurricane Bret on 22-23 August 1999 initialized with airborne Doppler radar and dropsonde data, Q. J. Roy. Meteorol. Soc., 131, 155-194, doi:10.1256/qj.02.233, 2005.

Pfister, L., Chan, K. R.,Bui, T. P., Bowen, S., Legg, M., Gary, B., Kelly, K., Proffitt, M., and Starr, W.: Gravity waves generated by a tropical cyclone during the step tropical field programm: A case study, J. Geophys. Res., 98, 8611-8638, 1993.

Piani, C., Durran, D., Alexander, M. J., and Holton, J. R.: A numerical study of three-dimensional gravity waves triggered by deep tropical convection and their role in the dynamics of the QBO, J. Atmos. Sci., 57, 3689-3702, 2000.

Pinty, J.-P. and Jabouille, P.: A mixed-phase cloud parameterization for use in mesoscale non-hydrostatic model: simulations of a squall line and of orographic precipitations, Proc. Conf. of Cloud Physics, Everett, WA, USA, Amer. Meteor. Soc., 217-220, 1998.

Pirscher, B., Foelsche, U., Borsche, M., Kirchengast, G., and Kuo, Y.-H.: Analysis of migrating diurnal tides detected in FORMOSAT-3/COSMIC temperature data, J. Geophys. Res., 115, D14108, doi:10.1029/2009JD013008, 2010.

Plougonven, R. and Teitelbaum, P. H.: Comparison of a largescale inertia gravity wave as seen in the ECMWF analyses and from radio-sondes, Geophys. Res. Lett., 30, 1954, doi:10.1029/2003GL017716, 2003.

Pratt, W. K.: Digital Image Processing: PIKS Inside, Third Edition, John Wiley \& Sons, Inc., New York, USA, 735 pp., 2001.

Preusse, P., Eckermann, S. D., and Ern, M.: Transparency of the atmosphere to short horizontal wavelength gravity waves, J. Geophys. Res., 113, D24104, doi:10.1029/2007JD009682, 2008

Reasor, P. D., Montgomery, M. T., Marks, F. D., and Gamache, J. F.: Low-wavenumber structure and evolution of the hurricane inner core observed by airborne dual-Doppler radar, Mon. Weather Rev., 128, 1653-1680, 2000.

Richter, J. H., Sassi, F., and Garcia, R. R.: Toward a physically based gravity wave source parameterization in a general circulation model, J. Atmos. Sci., 67, 136-156, 2010.

Roux, F., Chane-Ming, F., Lasserre-Bigorry, A., and Nuissier, O.: Structure and evolution of intense tropical cyclone Dina near La Réunion on 22 January 2002: GB-EVTD analysis of sin- 
gle Doppler radar observations, J. Atmos. Ocean. Technol., 21, 1501-1518, 2004.

Salby, M. L. and Garcia, R. R.: Transient response to localized episodic heating in the tropics. Part I: Excitation and short-time near-field behavior, J. Atmos. Sci., 44, 458-498, 1987.

Sato, K.: Small-scale wind disturbances observed by the MU radar during the passage of Typhoon Kelly, J. Atmos. Sci., 50, 518537, 1993.

Saunders, R., Matricardi, M., Brunel, P., English, S., Bauer, P., O'Keeffe, U., Francis, P., and Rayer, P.: RTTOV-8 science and validation report, NWP SAF report, Met Offce, Exeter, UK, 41 pp., 2005.

Schecter, D. A.: The spontaneous imbalance of an atmospheric vortex at high Rossby number, J. Atmos. Sci., 65, 2498-2521, 2008.

Schroeder, S., Preusse, P., Ern, M., and Riese, M.: Gravity waves resolved in ECMWF and measured by SABER, Geophys. Res. Lett., 36, L10805, doi:10.1029/2008GL037054, 2009.

Schubert, W. H., Rozoff, C. M., Vigh, J. L., McNoldy, B. D., and Kossin, J. P.: On the distribution of subsidence in the hurricane eye, Q. J. Roy. Meteorol. Soc., 133, 595-605, 2007.

Shapiro, L. J.: The asymmetric boundary layer flow under a translating hurricane, J. Atmos. Sci., 40, 1984-1998, 1983.

Shutts, G. J. and Vosper, S. B.: Stratospheric gravity waves revealed in NWP model forecasts, Q. J. Roy. Meteorol. Soc., 137, 303317, doi:10.1002/qj.7, 2011.

Sun, B., Reale, A., Seidel, D. J., and Hunt, D. C.: Comparing radiosonde and COSMIC atmospheric profile data to quantify differences among radiosonde types and the effects of imperfect collocation on comparison statistics, J. Geophys. Res., 115, D23104, doi:10.1029/2010JD014457, 2010.

Tsuda, T., Nishida, M., Rocken, C., and Ware, R. H.: A global morphology of gravity wave activity in the stratosphere revealed by the GPS occultation data (GPS/MET), J. Geophys. Res., 105, 7257-7273, 2000.

Vincent, R. A. and Alexander, M. J.: Gravity waves in the tropical lower stratosphere: An observational study of seasonal and interannual variability, J. Geophys. Res., 105, 17971-17982, doi:10.1029/2000JD900196, 2000.

Wang, Y.: Vortex Rossby waves in a numerically simulated tropical cyclone. Part I: Overall structure, potential vorticity and kinetic energy budgets, J. Atmos. Sci., 59, 1213-1238, 2002 a.
Wang, Y.: Vortex Rossby waves in a numerically simulated tropical cyclone. Part II: The role in tropical cyclone structure and intensity changes, J. Atmos. Sci., 59, 1239-1262, 2002b.

Wang, Y. and Wu, C.-C.: Current understanding of tropical cyclone structure and intensity changes - a review, Meteor. Atmos. Phys., 87, $257-278,2004$.

Willoughby, H. E.: A possible mechanism for the formation of hurricane rainbands, J. Atmos. Sci., 35, 838-848, 1978.

Wu, L. and Braun, S. A.: Effects of Environmentally Induced Asymmetries on Hurricane Intensity: A Numerical Study, J. Atmos. Sci., 61, 3065-3081, doi:10.1175/JAS-3343.1, 2004.

Xiao, C. Y. and Hu, X.: Analysis on the global morphology of stratospheric gravity wave activity deduced from the COSMIC GPS occultation profiles, GPS Solutions, 14, 65-74, doi:10.1007/s10291-009-0146-z, 2010.

Yu, Xing and Lee, Tae-Young: Role of convective parameterization in simulations of a convection band at grey-zone resolutions, Tellus, 62, 617-632, doi:10.1111/j.1600-0870.2010.00470.x, 2010.

Zhang, D.-L., Liu, Y. B., and Yau, M. K.: A multiscale numerical study of Hurricane Andrew (1992), Part III: Dynamically induced vertical motion, Mon. Weather Rev., 128, 3772-3788, 2000.

Zhang, D.-L., Liu, Y. B., and Yau, M. K.: A multiscale numerical study of hurricane Andrew (1992), Part IV: Inner-core thermodynamics, Mon. Weather Rev., 130, 2745-2763, 2002.

Zhang, K., Fu, E., Silcock, D., Wang, Y., and Kuleshov, Y.: An investigation of atmospheric temperature profiles in the Australian region using collocated GPS radio occultation and radiosonde data, Atmos. Meas. Tech., 4, 2087-2092, doi:10.5194/amt-42087-2011, 2011.

Zhang, Y., Xiong, J., Liu, L., and Wan, W.: A global morphology of gravity wave activity in the stratosphere revealed by the 8-yr SABER/TIMED data, J. Geophys. Res., 117, D21101, doi:10.1029/2012JD017676, 2012.

Zuiderveld, K.: Contrast limited adaptive histogram equalization, in: Graphics Gems IV, edited by: Heckbert, P., Academic Press, ISBN 0-12-336155-9, Academic Press Professional, San Diego, USA, 474-485, 1994. 